\title{
Multiobjective Optimization Method for Polymer Injection Molding Based on a Genetic Algorithm
}

\author{
Zhijun Yuan, ${ }^{1,2}$ Hui Wang ${ }^{D},{ }^{1}$ Xuebing Wei, ${ }^{2}$ Kui Yan, ${ }^{1}$ and Cheng Gao ${ }^{1}$ \\ ${ }^{1}$ Hubei Key Laboratory of Advanced Technology for Automotive Components, Wuhan University of Technology, Wuhan 430070, China \\ ${ }^{2}$ SAIC GM Wuling Automobile Company, Guangxi, Liuzhou 545007, China \\ Correspondence should be addressed to Hui Wang; huiwang@whut.edu.cn
}

Received 20 March 2019; Revised 7 June 2019; Accepted 3 July 2019; Published 24 July 2019

Guest Editor: Srikanth Pilla

Copyright (c) 2019 Zhijun Yuan et al. This is an open access article distributed under the Creative Commons Attribution License, which permits unrestricted use, distribution, and reproduction in any medium, provided the original work is properly cited.

\begin{abstract}
To solve the quality problem of polymer injection parts, a quality prediction and multiobjective optimization method is established. In this method, the parameters that have an important effect on the part quality are selected using an orthogonal testing method, and then a central composite design experiment is performed using these parameters. A mathematical model considering an objective and impact factors is developed using the response surface method. The optimal combination of the impact parameters is determined using a multiobjective genetic algorithm. The injection molding of a typical interior trim part of a car, i.e., the seat belt cover plate, is used as an example to demonstrate the method. The two most troublesome problems in this process-the sink marks and warpage-are multiobjectively analyzed using the established method, and the optimal combination of impact parameters that minimized the defects is determined. The errors of the sink marks and warpage between the experimental and theoretical values were $7.95 \%$ and $0.2 \%$, respectively. The optimized parameters were tested in actual injection molding. The results show that the shrinkage and warpage of the parts are obviously improved by optimization using the proposed method, allowing the parts to satisfy the requirements of assembly and appearance.
\end{abstract}

\section{Introduction}

Because of low cost, complex molding ability, convenience, light weight, and corrosion resistance, polymer injection parts are widely used around the world [1]. Currently, over $30 \%$ of all the plastic parts are manufactured by injection molding $[2,3]$, and $80 \%$ of engineering plastic products are manufactured by injection molding [4].

However, polymer injection molding, which involves various processing parameters, is a complex process [57], and the final parts may have quality problems if the processing parameters are not carefully selected. Thus, many studies have been performed to solve the quality problems by optimizing the processing parameters. Warpage, i.e., deviation of the shape of an injection part from that of the cavity, is one of the most common defects in the injection molding process [8]. Because of its adverse effects on the appearance and performance of polymer injection parts, warpage has attracted increasing attentions. Regarding the polymer injection molding of thin-walled parts, warpage is likely to occur in the manufacturing process, degrading the surface quality. Numerous researchers have attempted to minimize the warpage in the polymer injection molding process. Lee et al. [9] optimized the processing parameters, including the wall thickness of the injection parts, the injection time, the pressure, the packing and cooling times, the melt temperature, and the coolant temperature by using the modified complex method to prevent warpage. Ozcelik et al. $[10,11]$ used the software Moldflow, combined with a back propagation neural network and a hybrid genetic algorithm (GA), to reduce the warpage by optimizing parameters such as the mold temperature, the melt temperature, the packing pressure, and the packing and cooling times. S-H. Tang et al. [12] reduced the warpage by optimizing the mold temperature, the injection time, the pressure, and the packing time via an orthogonal experimental design method. Gao et al. [13] minimized the warpage for a telephone part using the Kriging model, concluding that the injection time played the greatest role in the warpage. Farshi et al. [14] reduced the warpage by optimizing the mold temperature, the melt 
temperature, the pressure, and the packing time. Wang et al. [15] optimized the warpage by improving the cooling system and processing parameters.

In the polymer injection molding of thin-wall parts, the warpage of parts is particularly obvious. By properly increasing the wall thickness of the part, its stiffness can be improved, and to a certain extent, the warpage can be reduced. However, shrinkage and dents are likely to occur during the injection molding of thicker wall parts. Rather than increasing the wall thickness, ribs are applied to increase the strength and stiffness of parts and effectively reduce the warpage. Thus, ribs are widely used in the design of injection parts. Nevertheless, ribs result in increased sink marks because of the thickness difference between a rib and its adjacent region. Deep sink marks seriously degrade the quality of injection parts.

Many studies have been performed on sink marks. Ni S. J. [16] reported that the geometric structure of parts, the mold structure, and the molding processing parameters were the main causes of sink marks. By combining experiments and a GA, Mathivanan D. [17] discovered that the melt temperature, the mold temperature, the packing pressure, and the ratio of the part thickness to the rib thickness were the most important factors for reducing sink marks. Guo et al. [1] experimentally studied the influence of parameters, such as the mold temperature, the melt temperature, the injection time, the V/P switch-over point, the packing pressure, the coolant temperature, the coolant Reynolds number, the direction of the rib, the thickness of the rib, and the distance between the rib and the injection gate on sink marks and optimized these parameters using a GA.

The optimization of the processing parameters was investigated in the aforementioned studies. However, most of the optimization methods considered only one objective. For different objectives, the optimized parameters may be different. The optimized parameters for one objective obtained by a single-objective optimization improve quality of the objective, but deteriorate quality of other objectives, such as the two objectives of warpage and sink marks. Guo et al. [1] showed that with the constant increase of the mold temperature between 20 and $80^{\circ} \mathrm{C}$, the warpage gradually decreased, and the sink marks first increased and then decreased. When the melt temperature was increased in the range of $220-280^{\circ} \mathrm{C}$, the warpage first increased and then decreased, while the sink marks constantly increased. When the packing pressure was increased in the range of $40 \%-120 \%$, the warpage first decreased and then increased, while the sink marks constantly decreased. When the packing time was increased in the range of 2.5-20 s, the warpage first increased and then decreased, while the sink marks first decreased and then remained constant. When the coolant temperature was increased in the range of $0-50^{\circ} \mathrm{C}$, the warpage first increased, and then decreased and became reduplicative, while the sink marks first increased and then decreased. Multiobjective optimization can not only be used to deal with these competing problems in injection molding $[18,19]$, but also is able to be used in other complex applications for novel design. In the innovative hybrid process that has been recently developed to manufacture metal-polymer composites, the multiobjective optimization can help to optimize the quality of polymeric part while still maintaining the requirement of sheet metal part $[20,21]$. In the manufacture of a hybrid material structure via the injection of polypropylene (PP) with high ductility into a robust CF/Epoxy thermoset sheet, the multiobjective optimization can be used to optimize the formability and joinability [22]. On the other hand, in the existing optimization models, selection of the impact factors was more subjective, and most of them were determined via simple analysis as well as experience, owing to lack of reliable data [23].

To rationally select the impact factors with regard to the quality objective for polymer injection molding and comprehensively optimize the quality of injection parts, a systematic method for multiobjectively predicting and optimizing the quality of polymer injection parts is established. In this method, the parameters that have important effects on the part quality are identified via orthogonal testing, and a central composite design (CCD) experiment is performed on these parameters. Then, a mathematical model considering the optimization objective and the impact factors is developed using a response surface method (RSM). Finally, the optimal combination of the impact parameters is determined using a multiobjective genetic optimization algorithm. The injection molding of the seat belt cover plate in a car was used as an example, and the two most prominent problems in this process, i.e., the sink marks and warpage, were multiobjectively optimized according to the established method.

This paper is organized as follows. Section 2 describes the established optimization method. Section 3 is the verification. Finally, Section 4 summarizes our conclusions.

\section{Multiobjective Optimization Method for Injection Molding}

2.1. Optimization Strategy. The optimization process for polymer injection molding can be described by the following mathematical model:

$$
\begin{array}{ll}
\text { Find } & \mathbf{x}=\left[x_{1}, x_{2}, \ldots, x_{m}\right]^{T} \\
\text { Min } & \mathbf{y}=\left[y_{1}, y_{2}, \ldots, y_{n}\right] \\
\text { S.T. } & x_{k \text { min }} \leq x_{k} \leq x_{k \text { max }}, \quad k=1,2, \ldots, m
\end{array}
$$

where $\mathbf{x}$ is the impact parameter vector, $x_{i}$ denotes an impact parameter associated with the injection molding quality, $m$ is the number of potential impact factors, $\mathbf{y}$ is the quality index vector of the polymer injection parts, $y_{j}$ is a quality index, $n$ is the number of concerned quality indices, and $x_{k \min }$ and $x_{k \max }$ denote the range of the impact parameters.

A method that can multiobjectively predict and optimize the quality of polymer injection molding is established. Its main flowchart is shown in Figure 1.

This method mainly includes a quality-factor selection module, a part-quality prediction module, and a multiobjective genetic optimization module. Firstly, for the qualityfactor selection module, a multifactor two-level orthogonal experiment is employed. By using mean-value analysis, the order of various factors that affect the quality of the injection 


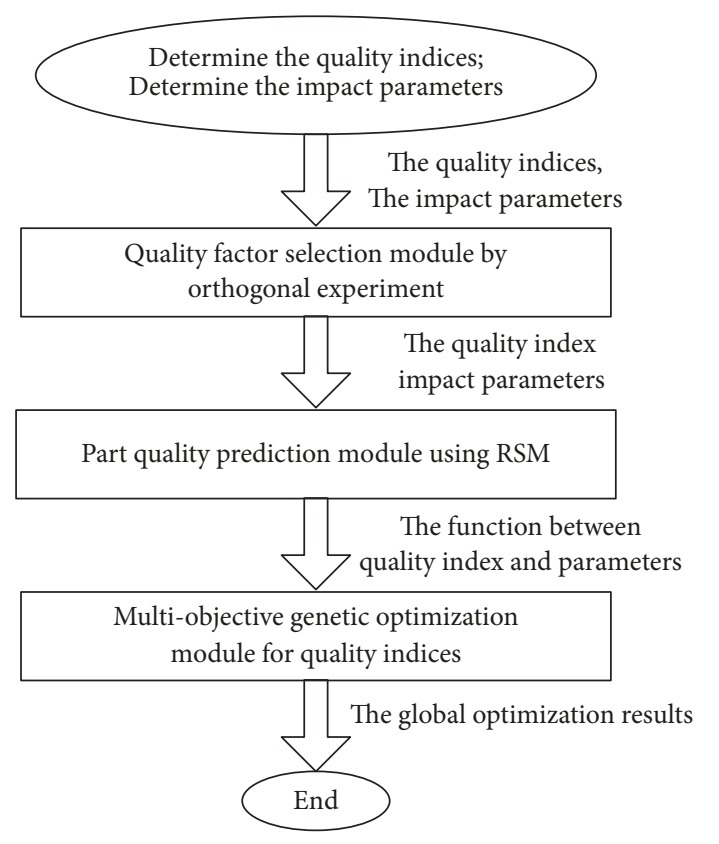

FIGURE 1: Flowchart of the method.

parts is identified, which provides scientific basis for choosing the quality impact factors. The part-quality prediction module based on the RSM is then applied to fit the single-objective function between the impact factors (such as processing parameters) and a target quality index according to CCD sample data. Finally, for the multiobjective genetic optimization module, the Pareto optimal solution set is obtained by using the Nondominated Sorting Genetic Algorithm II (NSGA-II) [24]. The design of the three aforementioned modules is described in detail in the following sections.

2.2. Quality-Factor Selection Module. In polymer injection molding, optimization can be performed from four aspects: the polymer resin, the part structure, the mold structure, and the processing parameters. For a specified part, the resin used is determined according to the performance and the cost, which are not easily changed. Therefore, the optimization is mainly realized by optimizing the part structure, the mold structure, and the processing parameters.

Orthogonal test design is a multifactor experimental design method wherein representative sample points are selected from the entire set of experimental sample points. The orthogonal test design is illustrated by the $\mathrm{L}_{4}\left(2^{3}\right)$ space model shown in Figure 2, where each axis represents a factor, the eight cube vertices represent eight experimental points in the overall experiment, and the four sample points (black points) determined by the orthogonal table are evenly distributed. The projections of the sample points along a single axis do not overlap. The orthogonal experimental design is applied to characterize the overall experiment by using fewer tests. The procedure comprises four steps: (1) determine the number of experimental factors and levels, (2) select the proper orthogonal table, (3) list the experimental scheme

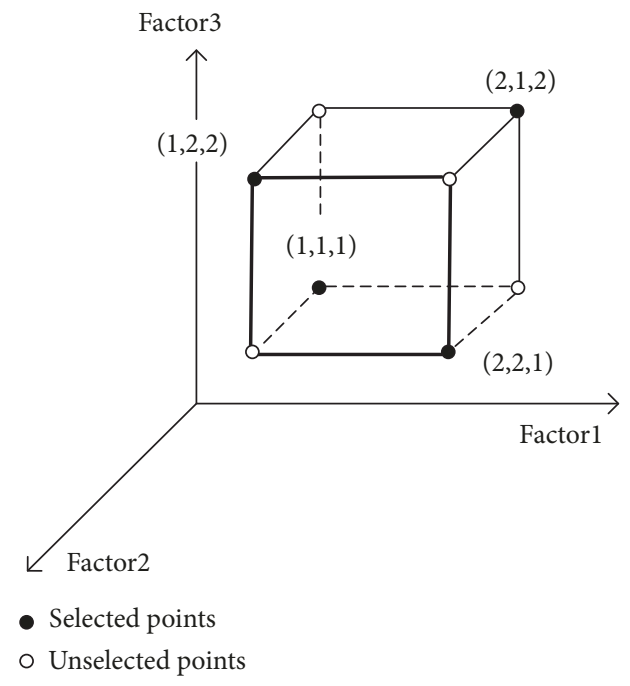

FIGURE 2: Space model of $\mathrm{L}_{4}\left(2^{3}\right)$.

and results, and (4) analyze the results of the orthogonal test design.

Before predicting and optimizing the quality of injection parts, the impact factors should be identified. The factors involved in the injection process are comprehensively considered. First, multifactor and two-level orthogonal design experiments are performed, and then several factors having the greatest effects on the injection parts are selected accordingly. For the multiobjective case, the influence of a factor on different objectives may be different.

The indices for the injection-part quality cannot be easily compared because of their different units and magnitudes, which is inconvenient for the comprehensive analysis of the indices. To eliminate this inconvenience, fuzzy mapping of the quality indices is applied. Here, each quality index is mapped to a fuzzy space $[0,1]$ and is made dimensionless. Various fuzzy functions can be used in actual applications, e.g., the triangle function, the trapezoid function, the Gaussian function, the ridge function, the parabolic function, and the $S$ shape function. In this study, the triangle fuzzy function is applied, which can be described as

$$
\mu(x)= \begin{cases}0 & x<a \\ \left(\frac{x-a}{b-a}\right)^{k} & a \leq x \leq b \\ 0 & x>b\end{cases}
$$

where $a, b$, and $k$ are the control parameters, which are determined by the index value.

Through fuzzy mapping, the quality index is translated to the space $[0,1]$. Thus, the comprehensive impact of each factor on the quality of the injection parts is easily determined via the mean analysis of the orthogonal-experiment results, providing scientific basis for the selection of the quality factors.

2.3. Part-Quality Prediction Module. An RSM is used to establish an approximate model for evaluating the response 
functions (quality indices) with respect to the design variables (impact factors), in order to perform prediction and optimization within the design space of the impact factors selected in Section 2.2.

When certain relationships exist between the impact factors and the response functions, a first- or second-order model describing the relationship between the responses and the impact factors can be obtained according to the experimental design. In the RSM, $y$ is generally assumed to be a quality index of a part or a process. The relationship between $y$ and the impact factors $x_{1}, x_{2} \ldots x_{\mathrm{k}}$ is given as follows:

$$
y=f\left(x_{1}, x_{2}, \ldots, x_{k}\right)+\varepsilon
$$

Here, the function $f$ is unknown and may be very complicated and $\varepsilon$ represents the error of the model. A first- or second-order Taylor expansion is generally used for the above function to approximate the real function over a small area. The first-order model is

$$
y=\beta_{0}+\sum_{i=1}^{k} \beta_{i} x_{i}+\varepsilon
$$

The second-order model is

$$
y=\beta_{0}+\sum_{i=1}^{k} \beta_{i} x_{i}+\sum_{i=1}^{k} \beta_{i i} x_{i}^{2}+\sum_{i<j} \sum_{j=2}^{k} \beta_{i j} x_{i} x_{j}+\varepsilon
$$

In these two models, $\varepsilon$ is random error, which follows a normal distribution. The random errors are independent of each other. The input variables are independent of each other.

The CCD is the most common and most recommended design in the RSM. It is an experimental design method based on two-level factors and partial experiments, wherein one zero point and two axial points are added for regression and evaluation of the relationship function between responses and factors.

2.4. Multiobjective Genetic Optimization Module. The idea of multiobjective optimization mainly studies on the simultaneous optimization of multiple objectives. Many scholars have proposed solutions for the multiobjective optimization problem, including the weighted-sum method, the goal programming method, the $\varepsilon$-constraint method, and other weight-based methods. With the development of artificial intelligence and its wide use in research and practice, many scholars have used artificial intelligence algorithms to solve multiobjective optimization problems. In this study, the quality of injection molding parts is optimized by the NSGAII genetic algorithm [24], and its Pareto optimal solution [25] set is obtained. The NSGA-II is developed from the classic GA. In the NSGA-II, multiobjective related operations are involved, such as the nondominated solution [26], the Pareto front [25], and the crowding distance [24], which are explained in Appendix A.

The solution process of the module includes population initialization, selection, crossover, and mutation, recombination, crowding distance calculation, nondominated sorting, population update, and the final Pareto solution set output.

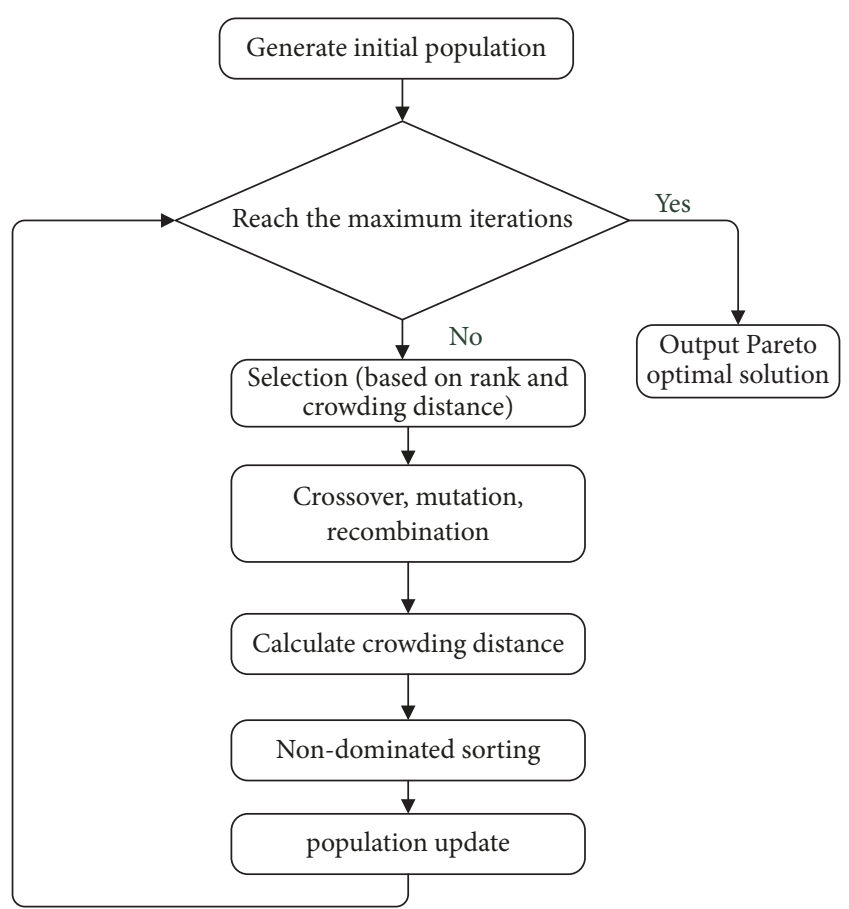

FIGURE 3: Flowchart of the NSGA-II.

The flowchart of the algorithm is shown in Figure 3. Algorithms of the key operators used in this module are provided in Appendix B.

2.5. Solving Process of the Method. Based on the method described above, its solving process is illustrated in Figure 4. First, quality indices concerned are identified for an injection part. Potential impact factors and their levels are preliminarily determined by experiences and trials. Then a multifactor two-level orthogonal experiment is performed, and the obtained quality indices are nondimensionalized by fuzzy mapping. The key impact factors are thus selected using mean-value analysis. Next, CCD experiment is performed for RSM, and each quality index is fitted as a singleobjective function of the impact factors. Among the fitted models, the best one is determined according to goodness of fit. Afterwards, the minimum/maximum values for an index are calculated using its fitted function, which are then used to nondimensionalize the index function by fuzzy mapping. Finally, multiobjective optimization is performed using NSGA-II to obtain the Pareto optimal solution set, from which the optimal solution is determined according to product requirements.

\section{Verification of the Method}

MATLAB programming was used to establish the aforementioned multiobjective intelligent optimization method, and the experimental design modules of Minitab were used to design and analyze the required experiments. A seatbelt cover plate of a vehicle, for which significant quality issues such as warpage and surface sink marks were observed during 


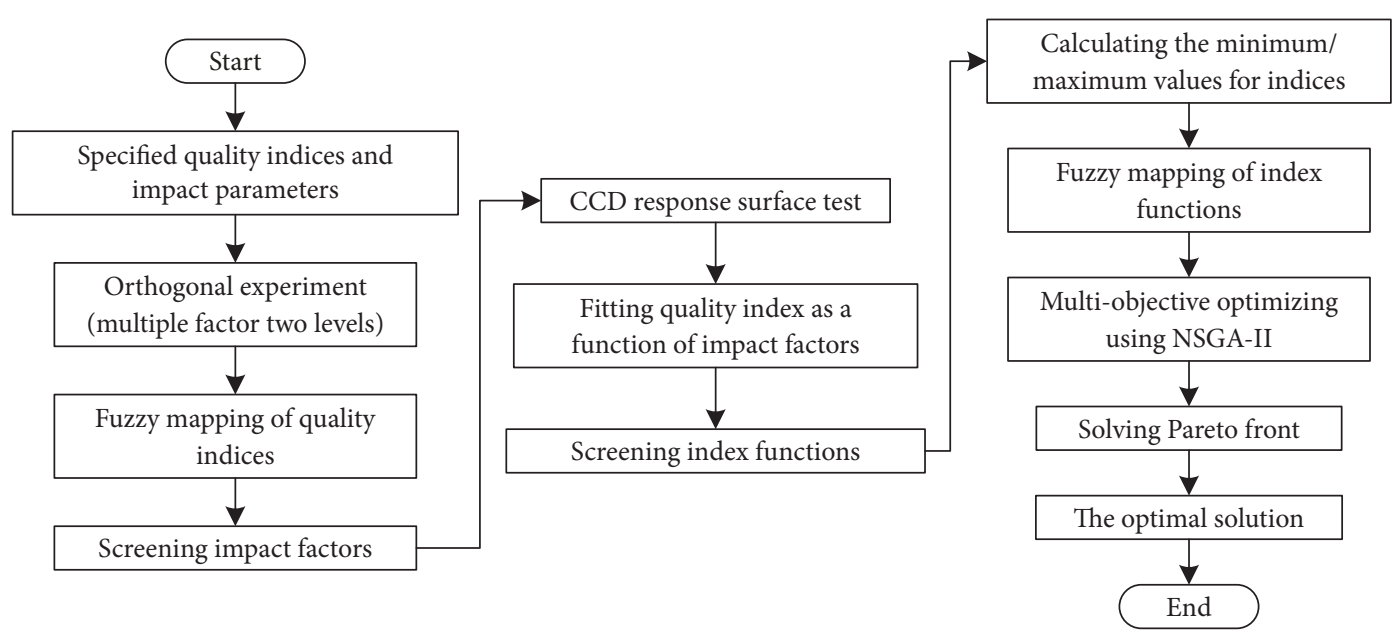

FIGURE 4: Solving process of the optimization method.

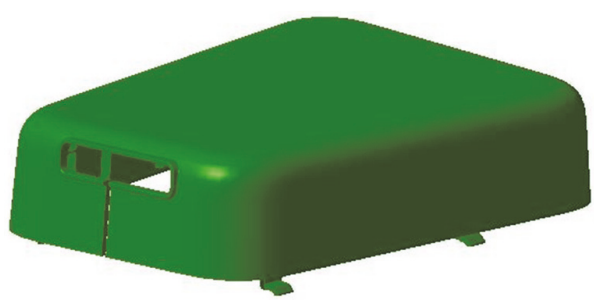

(a)

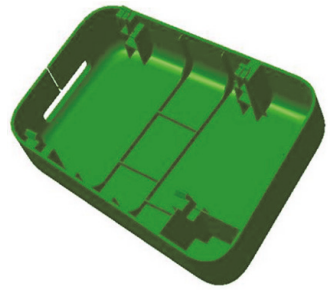

(b)

FIGURE 5: Seatbelt cover plate model: (a) outer shape and (b) inner details.

the injection molding process, was considered, and the established multiobjective optimization method for polymer injection molding was adopted to ameliorate the quality problems. For conducting the plastic injection process, one commercial injection molding software, Autodesk ${ }^{\circledR}$ Moldflow V2014, was used. It is widely used to analyze injection molding, and has a good accuracy [11, 27]. The software is hybrid finite-element/finite-difference method for solving pressure, flow and temperature fields [10], which can provide fill time, sink marks, warpage, air traps, weld line, stress, and other results.

\subsection{Case Setup}

3.1.1. Geometric Model. The three-dimensional model of the seatbelt cover plate considered in this study is shown in Figure 5.

3.1.2. Material. In accordance with the molding process for the cover plate, the material for computer-aided engineering analysis was selected as TK-PP1, and its properties are listed in Table 1.

3.1.3. Mold. The mold system for practical manufacturing was employed to obtain a more accurate simulation output corresponding to the actual process. The cooling and feeding
TABLE 1: Material properties of TK-PP1.

\begin{tabular}{lc}
\hline Material properties & Value \\
\hline Solid density $(\mathrm{g} / \mathrm{cm} 3)$ & 1.0866 \\
Melt density $(\mathrm{g} / \mathrm{cm} 3)$ & 0.90867 \\
Recommended mold temperature $\left({ }^{\circ} \mathrm{C}\right)$ & 30 \\
Recommended melt temperature $\left({ }^{\circ} \mathrm{C}\right)$ & 230 \\
Fibers/filler $($ talc-filled $)$ & $20 \%$ Talc \\
Material characteristics & $\mathrm{PP}$ \\
Elastic modulus $(\mathrm{MPa})$ & 2200 \\
Shear modulus $(\mathrm{MPa})$ & 2270 \\
Poisson's ratio & 0.39 \\
\hline
\end{tabular}

systems were set for the simulation analysis of the seatbelt cover, as shown in Figure 6.

\subsection{Factor Selection by Orthogonal Experiment}

\subsubsection{Experimental Factors}

(a) Part Structure. The thickness, the height, and the root fillet of the rib have significant effects on the cooling time of the injection process, thereby affecting the surface qualities of the injection part. These factors should be considered in the rib design. The rib thickness varies with the thickness of the molding parts, and the rib height is related to the rib 
TABLE 2: Experimental factors and their levels.

\begin{tabular}{|c|c|c|c|c|}
\hline \multirow{2}{*}{ No. } & \multirow{2}{*}{ Factors } & \multirow{2}{*}{ Abbr. } & \multicolumn{2}{|c|}{ Levels } \\
\hline & & & Low & High \\
\hline 1 & Rib radius $(\mathrm{mm})$ & $\mathrm{r}$ & 0 & 0.8 \\
\hline 2 & Rib relative thickness & $\mathrm{t}$ & 0.4 & 0.8 \\
\hline 3 & Rib relative height & $\mathrm{h}$ & 2 & 4 \\
\hline 4 & Sprue diameter (mm) & $\mathrm{d}$ & 6 & 12 \\
\hline 5 & Gate location & s & A & B \\
\hline 6 & Injection time (s) & $\mathrm{t}_{\text {inj. }}$ & 1.97 & 2.17 \\
\hline 7 & Melt temperature $\left({ }^{\circ} \mathrm{C}\right)$ & $\mathrm{T}_{\text {melt }}$ & 210 & 250 \\
\hline 8 & Mold temperature $\left({ }^{\circ} \mathrm{C}\right)$ & $\mathrm{T}_{\text {mold }}$ & 20 & 40 \\
\hline 9 & Coolant temperature $\left({ }^{\circ} \mathrm{C}\right)$ & $\mathrm{T}_{\text {cool }}$ & 10 & 40 \\
\hline 10 & Coolant time (s) & $\mathrm{t}_{\mathrm{cool}}$ & 20 & 50 \\
\hline 11 & The Re number of coolant & $\mathrm{RE}$ & 9000 & 11000 \\
\hline 12 & Cooling channel diameter (mm) & $\mathrm{D}$ & 8 & 12 \\
\hline 13 & $\mathrm{~V} / \mathrm{P}$ switch-over point & $\mathrm{V} / \mathrm{P}$ & $90 \%$ & $99 \%$ \\
\hline 14 & Packing pressure (MPa) & $\mathrm{P}_{\text {pack }}$ & 25 & 45 \\
\hline 15 & Packing time (s) & $\mathrm{t}_{\mathrm{pack}}$ & 6 & 14 \\
\hline
\end{tabular}

Annotation: (1) wall thickness of the physical model presented in Section 3.1 was $2.33 \mathrm{~mm}$.

(2) Diameter of the sprue was double that of the runner.

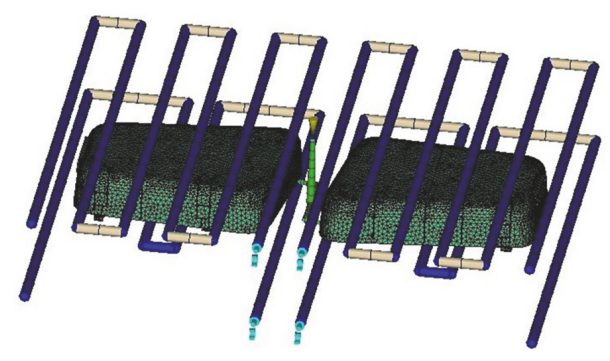

FIGURE 6: Simulation model.

thickness. Thus, the relative thickness (rib's/part's), relative height (height/thickness), and fillet angle radius of the rib were set as structural factors for the optimization of the surface quality of the cover plate.

(b) Mold Structure. Since the part structure and material were specified by the original designed manufacturer (ODM), the injection gate design of the mold becomes the key factor determining the ultimate quality of the molding part [2831]. The position and diameter of the gate-the two main geometric parameters of the gate-were considered.

(c) Processing Parameters. In accordance with previous reports $[9-16,32]$, the melt and the mold temperature, the cooling time and the temperature, the packing pressure and the time, the injection time, the V/P switch-over point, and the Re number of the cooling liquid were used as processing parameters to optimize the surface qualities. The coolingchannel diameter has a remarkable effect on the cooling process, which significantly influenced the surface quality. Therefore, it was also considered in the quality-optimization analysis.
3.2.2. Design and Results of Orthogonal Experiment. According to the aforementioned experimental parameters for the polymer injection part with ribs, the factors considered in this study and their levels for the multiobjective optimization method of the cover plate are listed in Table 2. The injection gate position of Level A is shown in Figure 6, and that of Level $\mathrm{B}$ is symmetrical to Level A.

Orthogonal-experiment design was performed using Minitab with the factors listed in Table 2. The designed experimental sequence is presented in Table 3.

Moldflow simulations were conducted in accordance with the combination of the parameters listed in Table 3. Contours of sink marks and warpage of the cases No. 6 and No. 16 are shown in Figure 7 for example. From this figure, it can be seen that sink marks are found in the surface of the cover plate, and distinct warpage is observed at the groove position. The contours of the other cases are similar, and the results are illustrated in Figure 8. The sink marks and warpage vary inconsistently as the parameters change, indicating the significance of the multiobjective optimization for the molding part. However, the simulation results for the sink marks and warpage differ significantly, and the magnitude ratio of them is about 100 .

3.2.3. Analysis of Orthogonal-Experiment Results. The fuzzy mapping of the indices is described in Section 2.2. The parameters $\mathrm{a}$ and $\mathrm{b}$ in the fuzzy functions for the sink marks and warpage, which are given by Eq. (2), were set as the minimum and maximum respectively, and $\mathrm{k}=1$ was assumed for simplification. The results are shown in Table 4.

The mapped values for the sink marks and warpage have the same order of magnitude after the fuzzy mapping. The results shown in Table 4 were orthogonally analyzed in Minitab, and the mean-value analysis is shown in Table 5. 


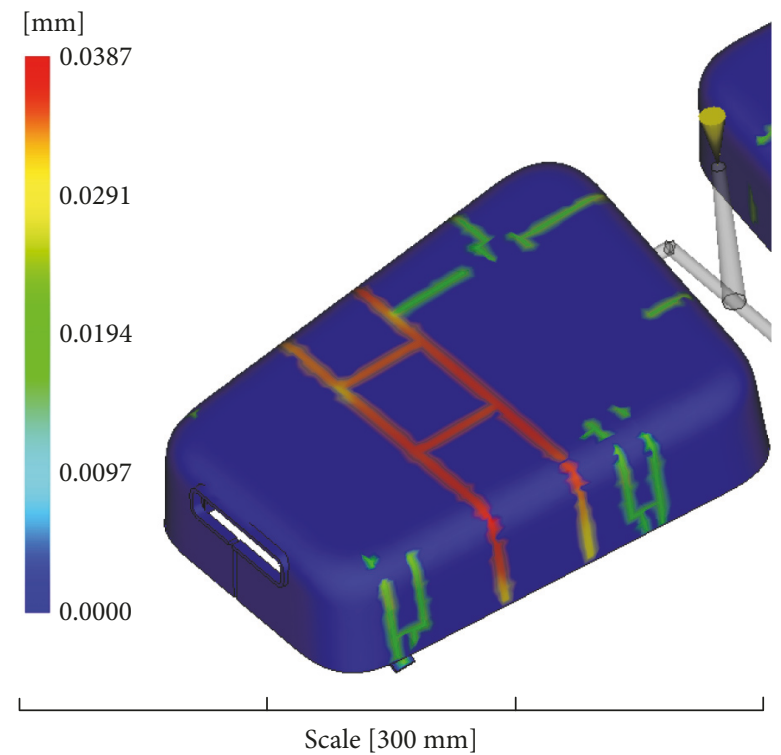

(a)

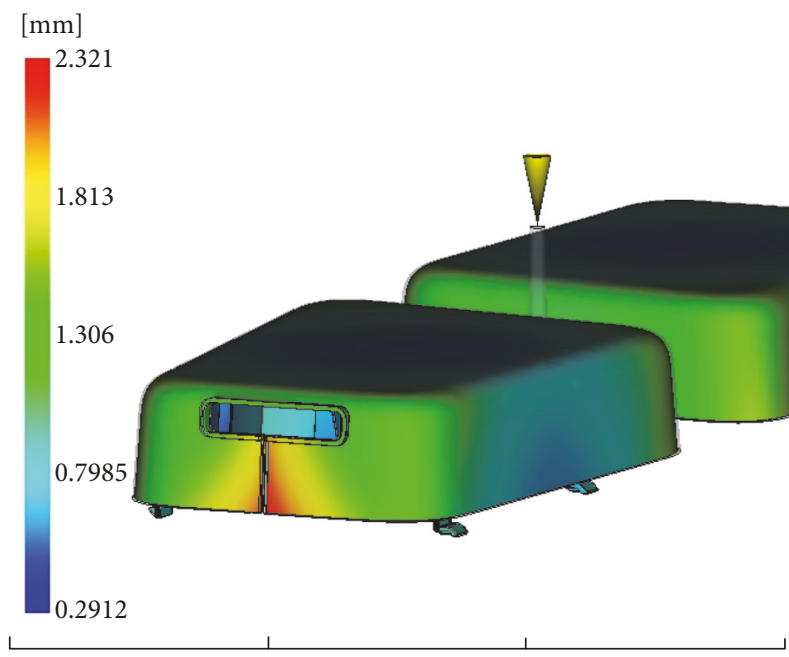

Scale $[300 \mathrm{~mm}]$

(c)

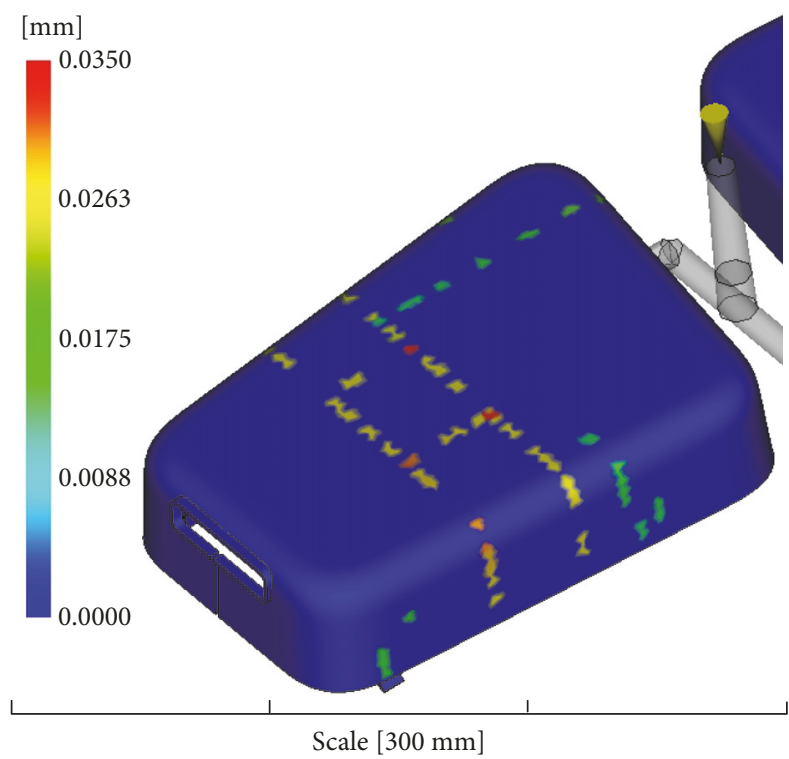

(b)

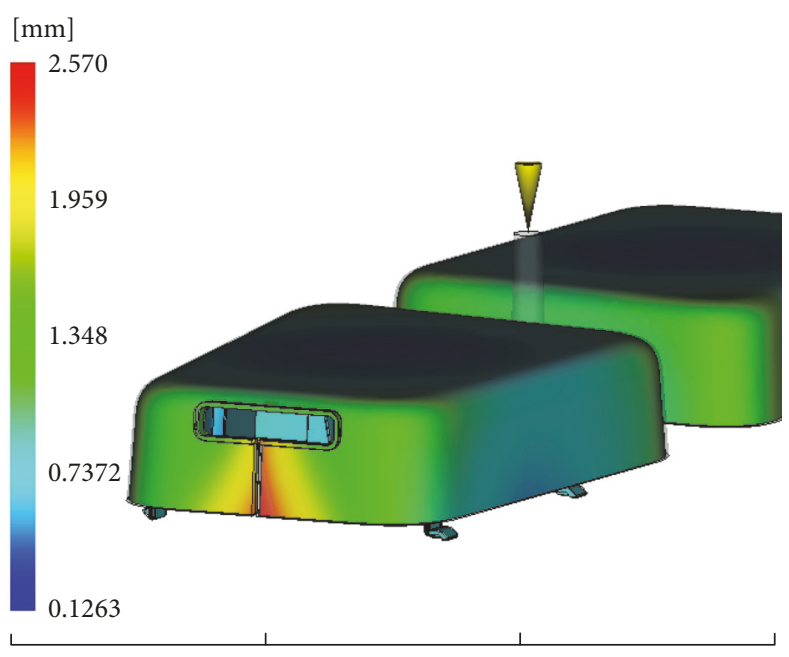

Scale $[300 \mathrm{~mm}]$

(d)

FIGURE 7: Contours of sink marks and warpage: (a) sink marks of Case No. 6, (b) sink marks of Case No. 16, (c) warpage of Case No. 6, and (d) warpage of Case No. 16.

From the mean-value analysis, the order of the influence of the factors is: the packing time, the mold temperature, the relative thickness of the rib, the melt temperature, the packing pressure, the V/P switch-over point, the radius of the rib fillets, the injection gate position, cooling-channel diameter, coolant temperature, cooling time, relative height of the rib, injection time, Re number of the coolant, and the sprue diameter.

The first five factors, which played dominant roles in the multiobjective optimization for the sink marks and warpage, were selected as the factors in the response surface experiment, to build the mathematical model for the sink marks and warpage versus the parameters, and thus the impact parameter vector $\mathbf{x}$ in Eq. (1) was identified.

\subsection{Index Fitting by RSM}

3.3.1. Design and Results of Response Surface Experiment. The levels for the five aforementioned factors are presented in Table 6, and the design for the response surface experiment using Minitab is shown in Table 7. The other ten parameters were set as the same with those in Case No.3 in the orthogonal test (Table 4), for the case exhibited the minimum value for the summation of the sink marks and warpage. Simulations were conducted in accordance with the response surface experiments detailed in Table 7, and the results are illustrated in Figure 9. From this figure, sink marks and warpage show different behaviors as the parameters change, and the relationship is discussed in the Sections 3.3.2 and 3.3.3. 
TABLE 3: Orthogonal test.

\begin{tabular}{|c|c|c|c|c|c|c|c|c|c|c|c|c|c|c|c|}
\hline No. & $\mathrm{r}$ & $\mathrm{t}$ & $\mathrm{h}$ & $\mathrm{d}$ & $\mathrm{s}$ & $t_{\text {inj }}$ & $\mathrm{T}_{\mathrm{me}}$ & $\mathrm{T}_{\mathrm{mo}}$ & $\mathrm{T}_{\mathrm{co}}$ & $t_{c o}$ & $\mathrm{RE}$ & $\mathrm{D}$ & $\mathrm{V} / \mathrm{P}$ & $\mathrm{P}$ & $t_{\mathrm{pa}}$ \\
\hline 1 & 1 & 1 & 1 & 1 & 1 & 1 & 1 & 1 & 1 & 1 & 1 & 1 & 1 & 1 & 1 \\
\hline 2 & 1 & 1 & 1 & 1 & 1 & 1 & 1 & 2 & 2 & 2 & 2 & 2 & 2 & 2 & 2 \\
\hline 3 & 1 & 1 & 1 & 2 & 2 & 2 & 2 & 1 & 1 & 1 & 1 & 2 & 2 & 2 & 2 \\
\hline 4 & 1 & 1 & 1 & 2 & 2 & 2 & 2 & 2 & 2 & 2 & 2 & 1 & 1 & 1 & 1 \\
\hline 5 & 1 & 2 & 2 & 1 & 1 & 2 & 2 & 1 & 1 & 2 & 2 & 1 & 1 & 2 & 2 \\
\hline 6 & 1 & 2 & 2 & 1 & 1 & 2 & 2 & 2 & 2 & 1 & 1 & 2 & 2 & 1 & 1 \\
\hline 7 & 1 & 2 & 2 & 2 & 2 & 1 & 1 & 1 & 1 & 2 & 2 & 2 & 2 & 1 & 1 \\
\hline 8 & 1 & 2 & 2 & 2 & 2 & 1 & 1 & 2 & 2 & 1 & 1 & 1 & 1 & 2 & 2 \\
\hline 9 & 2 & 1 & 2 & 1 & 2 & 1 & 2 & 1 & 2 & 1 & 2 & 1 & 2 & 1 & 2 \\
\hline 10 & 2 & 1 & 2 & 1 & 2 & 1 & 2 & 2 & 1 & 2 & 1 & 2 & 1 & 2 & 1 \\
\hline 11 & 2 & 1 & 2 & 2 & 1 & 2 & 1 & 1 & 2 & 1 & 2 & 2 & 1 & 2 & 1 \\
\hline 12 & 2 & 1 & 2 & 2 & 1 & 2 & 1 & 2 & 1 & 2 & 1 & 1 & 2 & 1 & 2 \\
\hline 13 & 2 & 2 & 1 & 1 & 2 & 2 & 1 & 1 & 2 & 2 & 1 & 1 & 2 & 2 & 1 \\
\hline 14 & 2 & 2 & 1 & 1 & 2 & 2 & 1 & 2 & 1 & 1 & 2 & 2 & 1 & 1 & 2 \\
\hline 15 & 2 & 2 & 1 & 2 & 1 & 1 & 2 & 1 & 2 & 2 & 1 & 2 & 1 & 1 & 2 \\
\hline 16 & 2 & 2 & 1 & 2 & 1 & 1 & 2 & 2 & 1 & 1 & 2 & 1 & 2 & 2 & 1 \\
\hline
\end{tabular}

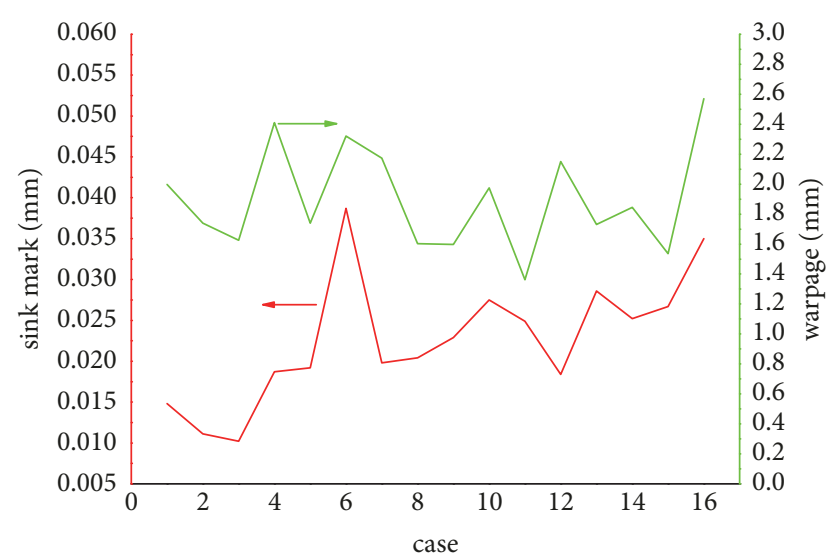

— Sink mark
— Warpage

FIGURE 8: Results of sink marks and warpage.

3.3.2. Fitting of Sink Marks. Four fitting models were calculated, i.e., pure quadratic, linear + parabolic, linear + interactive, and linear. Fitting of the simulation results was performed using these four models respectively to obtain the mathematical function. The sink marks in Figure 9 were input as a response to conduct the response surface experiment. The results are shown in Table 8.

Comparison of R-sq, R-sq (adjustment) and R-sq (prediction) implies that the linear fitting model was the best one to fit the relationship between the sink marks and all the parameters, and the model was applied in this study. The values of the regression coefficients in the fitting model are shown in Table 9.

In the table, Coeff represents the coefficients in the linear fitting model. SE Coeff represents the errors for the coefficients. A lower SE Coeff value indicates higher precision. The

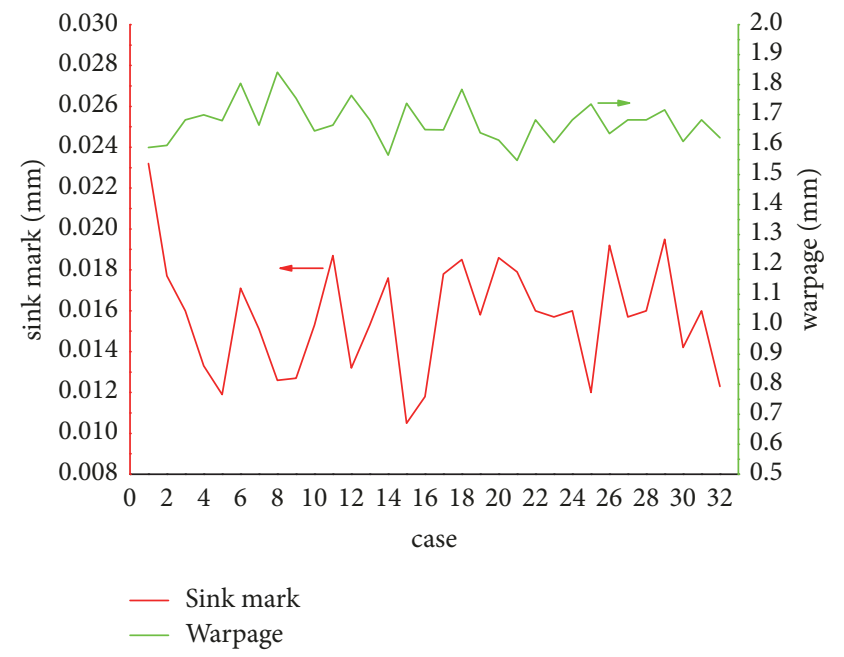

FIGURE 9: Results of sink marks and warpage.

SE Coeff values shown in Table 9 are small enough to ensure that the coefficients in the model are reasonable. T describes the ratio between the coefficient and its standard error, which is used to calculate the value P. P is set to assess the properties of the postulations. Factors with a low $\mathrm{P}$ value, especially less than 0.05 , have significant effects on the sink marks.

The residual plot between the prediction and experiment is shown in Figure 10, where the residuals cluster near the standard line. The maximum residual was $<0.003$. According to the frequency distribution, most residuals are within a low level. The accuracy of the model is thus demonstrated.

3.3.3. Fitting of Warpage. The response surface experiment and analysis in Section 3.3.2 was reproduced here to obtain the relationship between the warpage and the factors; however, we adopted the linear + parabolic model, instead. The 


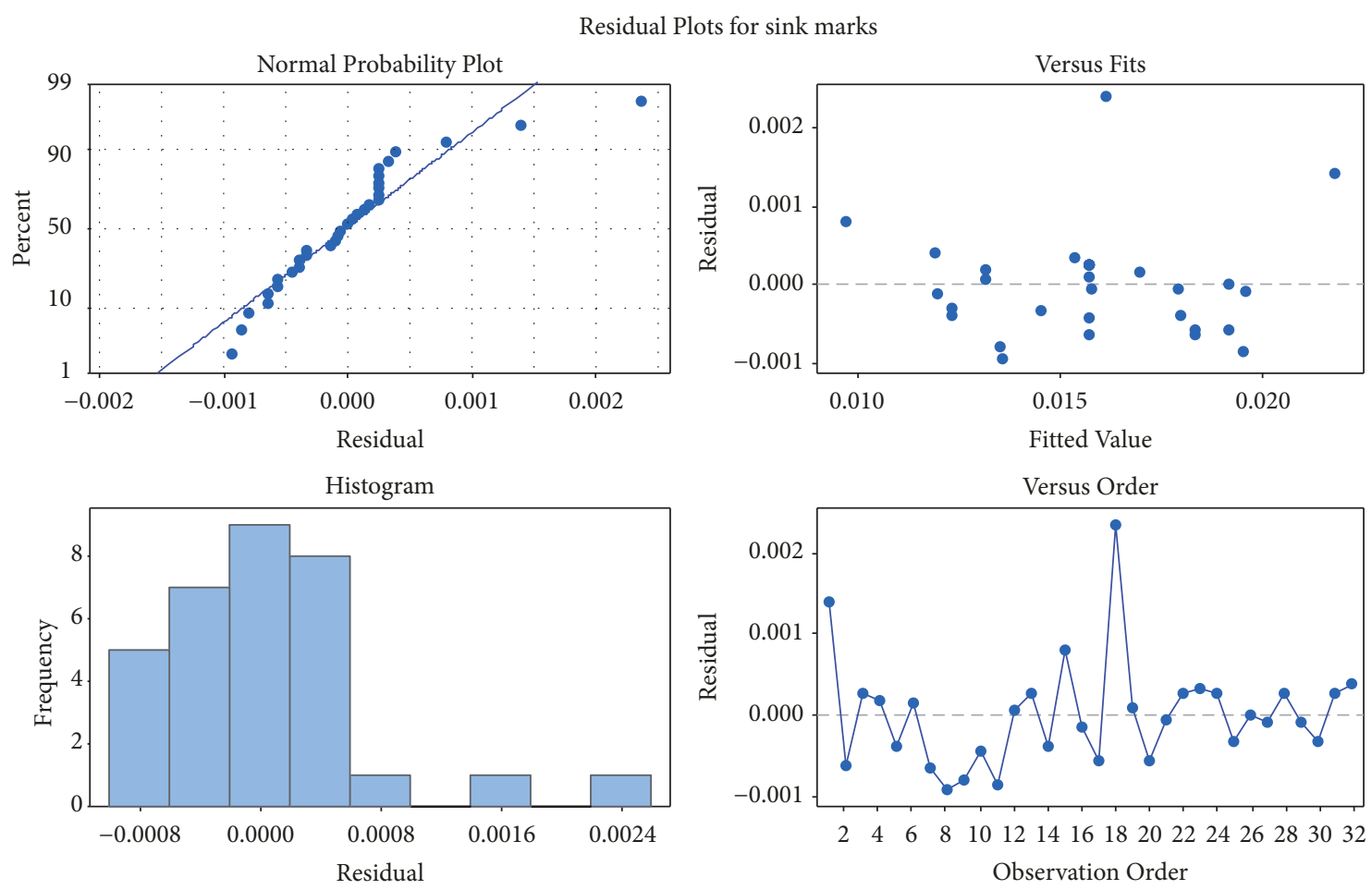

FIGURE 10: Residuals between the predicted and experimental values.

corresponding results are shown in Tables 10 and 11. Coeff, SE Coeff, T and P were similarly employed for the analysis of the warpage. Thus the quality index vector $y$ in Eq. (1) was identified.

\subsection{Multiobjective Optimization}

3.4.1. Optimization Using GA. The multiobjective optimization of the surface qualities during the injection molding of the seatbelt cover plate were developed according to the regression fitting for the sink marks and warpage presented in the Sections 3.3.2 and 3.3.3, and the mathematical model of Eq. (1) is written as:

$$
\begin{aligned}
& \text { Find } \quad[\mathrm{A}, \mathrm{B}, \mathrm{C}, \mathrm{D}, \mathrm{E}] \\
& \operatorname{Min} \quad\left[y_{1}, y_{2}\right] \\
& \begin{aligned}
& y_{1} \\
&= 0.015875-0.000292 \times \mathrm{A}+0.000042 \times \mathrm{B} \\
&+0.003042 \times \mathrm{C}-0.000042 \times \mathrm{D}-0.000625 \\
& \times \mathrm{E} \\
& y_{2} \\
&= 1.68272-0.03713 \times \mathrm{A}-0.00171 \times \mathrm{B} \\
& \quad-0.04379 \times \mathrm{C}-0.01929 \times \mathrm{D}-0.04304
\end{aligned}
\end{aligned}
$$

$$
\begin{aligned}
& \times \mathrm{E}+0.00266 \times \mathrm{A} \times \mathrm{A}-0.00747 \times \mathrm{B} \times \mathrm{B} \\
& -0.00522 \times \mathrm{C} \times \mathrm{C}-0.00609 \times \mathrm{D} \times \mathrm{D} \\
& +0.00553 \times \mathrm{E} \times \mathrm{E}
\end{aligned}
$$

$$
\text { S.T. } \quad-2<\mathrm{A}, \mathrm{B}, \mathrm{C}, \mathrm{D}, \mathrm{E}<2
$$

Where, $y_{1}$ and $y_{2}$ denote the sink marks and warpage respectively, $\mathrm{A}, \mathrm{B}, \mathrm{C}, \mathrm{D}$, and $\mathrm{E}$ are the impact parameters in Table 6.

The multiobjective genetic algorithm was used to perform the optimization. The multiobjective optimization was implemented by the following steps:

Step 1. The minimum/maximum values for sink marks $\left(\mathrm{Min}_{\mathrm{SK}} / \mathrm{Max}_{\mathrm{SK}}\right)$ and warpage $\left(\mathrm{Min}_{\mathrm{war}} / \mathrm{Max}_{\mathrm{war}}\right)$ were determined within the specified domain of the impact factors by using the min and max functions.

Step 2. The objective functions (sink marks and warpage) were fuzzily mapped using Eq. (2), where the parameters $a$ and $b$ for the sink marks and warpage were set as the minimum and maximum respectively, and $\mathrm{k}=1$ was used. The mapped objective functions were set as the multiobjective fitness functions and were described as

$$
\begin{aligned}
& f_{1}=\frac{1}{\left(\operatorname{Max}_{\mathrm{SK}}-\operatorname{Min}_{\mathrm{SK}}\right)}\left(y_{1}-\operatorname{Min}_{\mathrm{SK}}\right) \\
& f_{2}=\frac{1}{\left(\operatorname{Max}_{\mathrm{war}}-\operatorname{Min}_{\mathrm{war}}\right)}\left(y_{2}-\operatorname{Min}_{\mathrm{war}}\right)
\end{aligned}
$$


TABLE 4: Fuzzy mapping of the orthogonal results.

\begin{tabular}{lccc}
\hline No. & Sink mark & Warpage & Sum \\
\hline 1 & 0.1614 & 0.5265 & 0.6879 \\
2 & 0.0316 & 0.3129 & 0.3445 \\
3 & 0.0000 & 0.2185 & 0.2185 \\
4 & 0.2982 & 0.8675 & 1.1658 \\
5 & 0.3158 & 0.3121 & 0.6279 \\
6 & 1.0000 & 0.7939 & 1.7939 \\
7 & 0.3368 & 0.6722 & 1.0090 \\
8 & 0.3579 & 0.1987 & 0.5566 \\
9 & 0.4456 & 0.1945 & 0.6402 \\
10 & 0.6070 & 0.5066 & 1.1136 \\
11 & 0.5158 & 0.0000 & 0.5158 \\
12 & 0.2877 & 0.6531 & 0.9409 \\
13 & 0.6456 & 0.3046 & 0.9502 \\
14 & 0.5263 & 0.3998 & 0.9262 \\
15 & 0.5789 & 0.1440 & 0.7230 \\
16 & 0.8702 & 1.0000 & 1.8702 \\
\hline
\end{tabular}

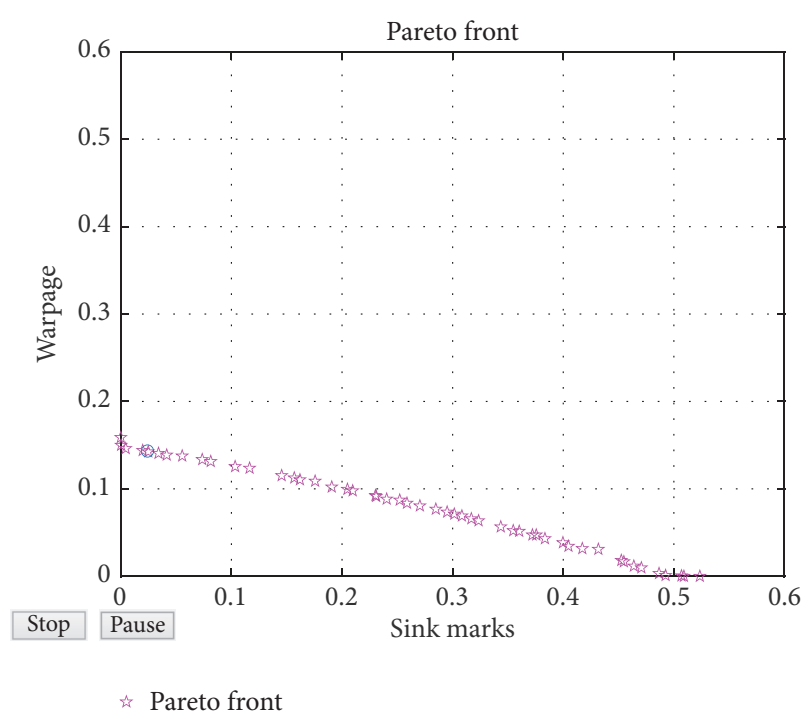

FIGURE 11: Solution of the GA.

Step 3. The optimal front set, population, and fitness function deviation were set to be 50,200, and 1e-100. The multiobjective genetic algorithm was used to calculate its Pareto optimal solution set, and the result is shown in Figure 11. In this figure, the points are the nondominated solutions of the problem, and each solution represents a combination of the parameters in Table 6. For the solution of the left end point, the sink marks are the best, but the warpage is the worst. The closer a solution is to the left end, the better the sink marks become, and the worse the warpage becomes. On the contrary, for the solution of the right end point, the warpage is the best, but the sink marks are the worst. The closer a solution is to the right end, the better the warpage is, and the worse the sink marks are. According to the requirements of the quality of the seatbelt cover, sink marks and warpage are both very important, so the nearest solution to the origin (least square) was selected as the final solution of this study. The optimal parameters were obtained: a packing time of 13.748 $\mathrm{s}$, mold temperature of $20.1325^{\circ} \mathrm{C}$, relative rib thickness of 0.40123 , melt temperature of $248.851^{\circ} \mathrm{C}$, and packing pressure of $44.512 \mathrm{MPa}$. The combination of these parameters yielded a maximum sink mark of $0.0081 \mathrm{~mm}$ and warpage of 1.5433 $\mathrm{mm}$.

3.4.2. Verification Experiment. The aforementioned parameters given by the GA were adopted in the simulation of Moldflow to verify the reliability of the optimization for the sink marks and warpage of the cover plate. The simulation results under the optimized parameters are shown in Figure 12, and those under the parameters of Level "2 ", "0", and " 2 " in Table 6 are provided in Figure 13 for comparison. Parameters of Level " -2 " and " 2 " are minimum and maximum values of the processing factors, and those of Level " 0 " are mean values. Compared with the other results, sink marks and warpage of the optimized results are both decreased obviously, which directly demonstrates effect of the optimization. It is noted that sink marks and warpage of the optimized results are not the minimal ones among all the results for this optimization. The warpage under the parameters of Level " 2 " in Figure 13(f) is smaller than that under the optimized parameters in Figure 12(b), but the sink marks are much worse. The results under the optimized parameters are not the best for a single objective but are the optimal for all of the objects. The simulation results under the optimized parameters are $0.0088 \mathrm{~mm}$ for the sink marks and $1.578 \mathrm{~mm}$ for the warpage. Compared with the optimization result by the GA, the errors are small: $0.0007 \mathrm{~mm}(7.95 \%)$ for the sink marks and $0.00347 \mathrm{~mm}(0.2 \%)$ for the warpage. Thus, the accuracy of the multiobjective optimization for the surface quality of the injection cover plate is high.

The optimized processing parameters were then adopted for the actual injection molding of the part. The manufactured cover plates are shown in Figure 14. Figures 14(a) and 14(c) show those without optimization, and the packing time of $10.0 \mathrm{~s}$, mold temperature of $30.0^{\circ} \mathrm{C}$, relative rib thickness of 0.6 , melt temperature of $230.0^{\circ} \mathrm{C}$, and packing pressure of $35 \mathrm{MPa}$ were used, which took the parameters of Level " 0 " in Table 6. The other parameters were set as the same with those in Case No. 3 in Table 4. Obvious sink marks are observed in Figure 14(a) because of the rib design and molding process. Warpage occurred at the groove position of the cover plate owing to the molding process. Both of these seriously degraded the appearance of the cover plate. Figures 14(b) and 14(d) show parts manufactured with the optimized parameters, and the packing time of $13.7 \mathrm{~s}$, mold temperature of $20.0^{\circ} \mathrm{C}$, relative rib thickness of 0.4 , melt temperature of $250^{\circ} \mathrm{C}$, and packing pressure of $44.5 \mathrm{MPa}$ were used, which approximated the optimized processing parameters as closely as possible. Comparison of Figures 14(a) and 14 (b) reveals that the sink marks disappeared after the optimization. Likewise, Figures 14(c) and 14(d) indicate that the warpage was improved distinctly. Measurements showed that the warpage at the groove position of the cover plate was $64.8 \%$ without optimization and $35.4 \%$ with optimization. 
TABLE 5: Results of mean-value analysis.

\begin{tabular}{|c|c|c|c|c|c|c|c|c|c|c|c|c|c|c|c|}
\hline Label & $\mathrm{r}$ & $\mathrm{t}$ & $\mathrm{h}$ & $\mathrm{d}$ & $\mathrm{s}$ & $t_{\text {inj }}$ & $\mathrm{T}_{\text {melt }}$ & $\mathrm{T}_{\text {mold }}$ & $\mathrm{T}_{\text {cool }}$ & $t_{\text {cool }}$ & $\mathrm{RE}$ & $\mathrm{D}$ & $\mathrm{V} / \mathrm{P}$ & $\mathrm{P}_{\text {pack }}$ & $t_{\text {pack }}$ \\
\hline 1 & 0.8005 & 0.7034 & 0.8608 & 0.8855 & 0.938 & 0.8681 & 0.7414 & 0.6716 & 0.9243 & 0.9012 & 0.8731 & 0.93 & 0.7896 & 0.9859 & 1.1383 \\
\hline 2 & 0.96 & 1.0571 & 0.8997 & 0.875 & 0.8225 & 0.8924 & 1.0191 & 1.089 & 0.8362 & 0.8594 & 0.8875 & 0.8306 & 0.9709 & 0.7747 & 0.6222 \\
\hline Delta & 0.1595 & 0.3537 & 0.0389 & 0.0106 & 0.1155 & 0.0243 & 0.2778 & 0.4174 & 0.088 & 0.0418 & 0.0144 & 0.0994 & 0.1813 & 0.2112 & 0.5161 \\
\hline Rank & 7 & 3 & 12 & 15 & 8 & 13 & 4 & 2 & 10 & 11 & 14 & 9 & 6 & 5 & 1 \\
\hline
\end{tabular}

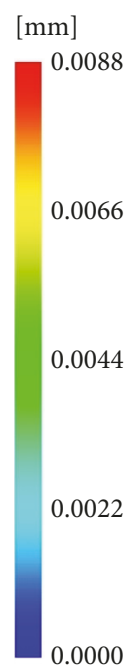

0.0000

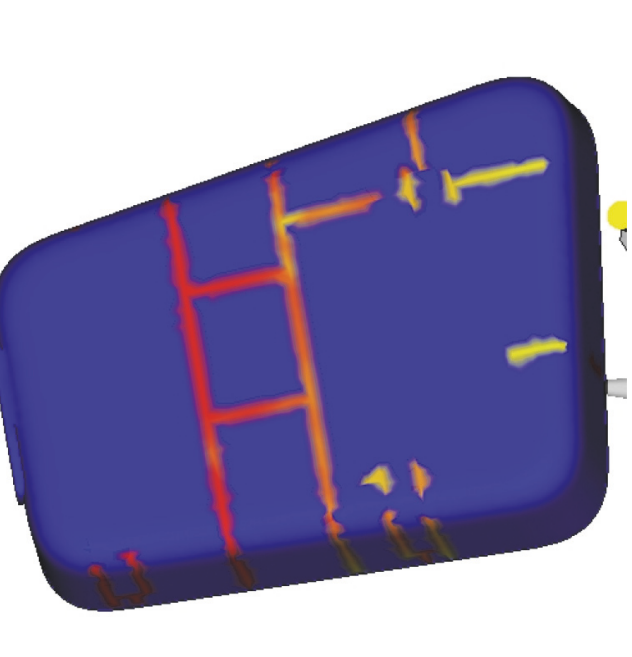

(a)

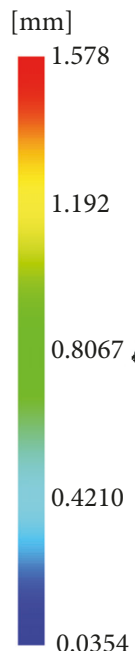

0.0354

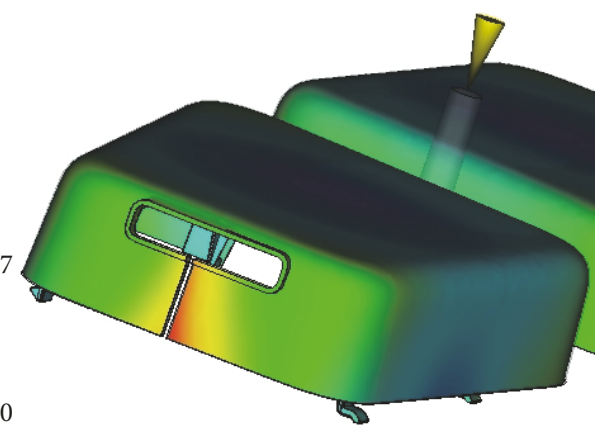

(b)

FIGURE 12: Simulation results under the optimized parameters: (a) sink marks and (b) warpage.

TABLE 6: Experimental factors and their levels.

\begin{tabular}{lccccc}
\hline Level & $\begin{array}{c}\mathrm{t}_{\text {pack }} \\
\mathrm{A}\end{array}$ & $\begin{array}{c}\mathrm{T}_{\text {mold }} \\
\mathrm{B}\end{array}$ & $\begin{array}{c}\mathrm{t} \\
\mathrm{C}\end{array}$ & $\begin{array}{c}\mathrm{T}_{\text {melt }} \\
\mathrm{D}\end{array}$ & $\begin{array}{c}\mathrm{P}_{\text {pack }} \\
\mathrm{E}\end{array}$ \\
\hline-2 & 6 & 20 & 0.4 & 210 & 25 \\
-1 & 8 & 25 & 0.5 & 220 & 30 \\
0 & 10 & 30 & 0.6 & 230 & 35 \\
1 & 12 & 35 & 0.7 & 240 & 40 \\
2 & 14 & 40 & 0.8 & 250 & 45 \\
\hline
\end{tabular}

The optimized result satisfied the appearance requirement of $<40 \%$.

\section{Conclusions}

We established a method of quality prediction and multiobjective optimization for injection molding. Firstly, the key impact factors for the objectives to be optimized are determined via orthogonal experiments. Secondly, RSM are performed to determine relationship function between an objective and impact factors. Finally, to determine the optimal combination of the impact factors, multiobjective GA is employed. The established optimization method was applied to the injection molding of a seatbelt cover plate as an example. The sink marks and warpage were selected as two objectives, which are two of the most prominent quality problems. We optimized the sink marks and warpage, and the prediction error was $<8 \%$. We used the optimized processing parameters to perform actual injection molding. The sink marks and warpage were significantly reduced, satisfying the requirements of actual assembly.

By analyzing the seatbelt cover by the proposed method, we confirmed the validity and accuracy of it. The proposed method provides not only scientific guidance for the injection molding process but also solutions and ideas for the multiobjective optimization of other similar problems. The authors intend to develop an integrated system by coding in MATLAB based on the established multiobjective optimization method, including user interfaces, experimental data input, factor selection, quality prediction, and optimization, and apply it in design of TPE (Thermoplastic Elastomer) overmolding.

\section{Appendix}

\section{A. Specific Operations Used in Multiobjective Optimization}

A.1. Nondominated Solution. Suppose $\mathrm{p}$ and $\mathrm{q}$ are two of all the feasible solutions. If at least one objective value for $\mathrm{p}$ is better than that of $q$ and all the other objective values for $p$ are not worse than those of q, it is defined as p dominates q or $\mathrm{q}$ is dominated by $\mathrm{p}$. Dominant and nondominant solutions are illustrated in Figure 15. Points 1, 2, 3, and 4 represent four feasible solutions. In an optimization problem for the 
TABLE 7: RSM experiments.

\begin{tabular}{|c|c|c|c|c|c|}
\hline No. & $\mathrm{A}$ & $\mathrm{B}$ & $\mathrm{C}$ & $\mathrm{D}$ & $\mathrm{E}$ \\
\hline 1 & 0 & 0 & 2 & 0 & 0 \\
\hline 2 & -1 & -1 & 1 & 1 & 1 \\
\hline 3 & 0 & 0 & 0 & 0 & 0 \\
\hline 4 & 1 & 1 & -1 & 1 & -1 \\
\hline 5 & -1 & 1 & -1 & 1 & 1 \\
\hline 6 & 0 & 0 & 0 & 0 & -2 \\
\hline 7 & 0 & -2 & 0 & 0 & 0 \\
\hline 8 & -1 & 1 & -1 & -1 & -1 \\
\hline 9 & -1 & -1 & -1 & 1 & -1 \\
\hline 10 & 0 & 2 & 0 & 0 & 0 \\
\hline 11 & -1 & 1 & 1 & 1 & -1 \\
\hline 12 & 1 & -1 & -1 & -1 & -1 \\
\hline 13 & 0 & 0 & 0 & 0 & 0 \\
\hline 14 & 1 & -1 & 1 & -1 & 1 \\
\hline 15 & 0 & 0 & -2 & 0 & 0 \\
\hline 16 & 1 & 1 & -1 & -1 & 1 \\
\hline 17 & -1 & 1 & 1 & -1 & 1 \\
\hline 18 & -2 & 0 & 0 & 0 & 0 \\
\hline 19 & 0 & 0 & 0 & 2 & 0 \\
\hline 20 & 1 & -1 & 1 & 1 & -1 \\
\hline 21 & 1 & 1 & 1 & 1 & 1 \\
\hline 22 & 0 & 0 & 0 & 0 & 0 \\
\hline 23 & 2 & 0 & 0 & 0 & 0 \\
\hline 24 & 0 & 0 & 0 & 0 & 0 \\
\hline 25 & -1 & -1 & -1 & -1 & 1 \\
\hline 26 & 1 & 1 & 1 & -1 & -1 \\
\hline 27 & 0 & 0 & 0 & -2 & 0 \\
\hline 28 & 0 & 0 & 0 & 0 & 0 \\
\hline 29 & -1 & -1 & 1 & -1 & -1 \\
\hline 30 & 0 & 0 & 0 & 0 & 2 \\
\hline 31 & 0 & 0 & 0 & 0 & 0 \\
\hline 32 & 1 & -1 & -1 & 1 & 1 \\
\hline
\end{tabular}

TABLE 8: Fitting results of the sink marks using the four regression models.

\begin{tabular}{lcccc}
\hline & R-sq & R-sq (adjustment) & R-sq (prediction) & $\begin{array}{c}\text { regression } \\
\text { model }\end{array}$ \\
\hline Quadratic & $97.51 \%$ & $93.00 \%$ & $37.95 \%$ & Sink mark1 \\
Linear + parabolic & $97.26 \%$ & $95.96 \%$ & $87.72 \%$ & Sink mark2 \\
Linear + interaction & $94.61 \%$ & $89.56 \%$ & $34.85 \%$ & Sink mark3 \\
Linear & $94.36 \%$ & $93.28 \%$ & $91.02 \%$ & Sink mark4 \\
\hline
\end{tabular}

Annotation: R-sq was the goodness coefficient in regression fitting models.

Results for the four regression models:

Sink mark1 $=0.016148-0.000292 \mathrm{~A}+0.000042 \mathrm{~B}+0.003042 \mathrm{C}-0.00004 \mathrm{D}-0.000625 \mathrm{E}+0.000227 \mathrm{~A} \times \mathrm{A}-0.000273 \mathrm{~B} \times \mathrm{B}+0.000102 \mathrm{C} \times \mathrm{C}-0.000148 \mathrm{D} \times \mathrm{D}-$ $0.000273 \mathrm{E} \times \mathrm{E}+0.000063 \mathrm{~A} \times \mathrm{B}-0.000062 \mathrm{~A} \times \mathrm{C}+0.000062 \mathrm{~A} \times \mathrm{D}+0.000062 \mathrm{~A} \times \mathrm{E}-0.000063 \mathrm{~B} \times \mathrm{C}+0.000063 \mathrm{~B} \times \mathrm{D}+0.000063 \mathrm{~B} \times \mathrm{E}-0.000063 \mathrm{C} \times \mathrm{D}-0.000063 \mathrm{C} \times \mathrm{E}$ $+0.000063 \mathrm{D} \times \mathrm{E}$.

Sink mark $2=0.016148-0.000292 \mathrm{~A}+0.000042 \mathrm{~B}+0.003042 \mathrm{C}-0.000042 \mathrm{D}-0.000625 \mathrm{E}+0.000227 \mathrm{~A} \times \mathrm{A}-0.000273 \mathrm{~B} \times \mathrm{B}+0.000102 \mathrm{C} \times \mathrm{C}-0.000148 \mathrm{D} \times \mathrm{D}-$ $0.000273 \mathrm{E} \times \mathrm{E}$.

Sink mark $3=0.015875-0.000292 \mathrm{~A}+0.000042 \mathrm{~B}+0.003042 \mathrm{C}-0.000042 \mathrm{D}-0.000625 \mathrm{E}+0.000063 \mathrm{~A} \times \mathrm{B}-0.000062 \mathrm{~A} \times \mathrm{C}+0.000062 \mathrm{~A} \times \mathrm{D}+0.000063 \mathrm{~A} \times \mathrm{E}-$ $0.000063 \mathrm{~B} \times \mathrm{C}+0.000063 \mathrm{~B} \times \mathrm{D}+0.000063 \mathrm{~B} \times \mathrm{E}-0.000063 \mathrm{C} \times \mathrm{D}-0.000063 \mathrm{C} \times \mathrm{E}+0.000063 \mathrm{D} \times \mathrm{E}$.

Sink mark $4=0.015875-0.000292 \mathrm{~A}+0.000042 \mathrm{~B}+0.003042 \mathrm{C}-0.000042 \mathrm{D}-0.000625 \mathrm{E}$. 


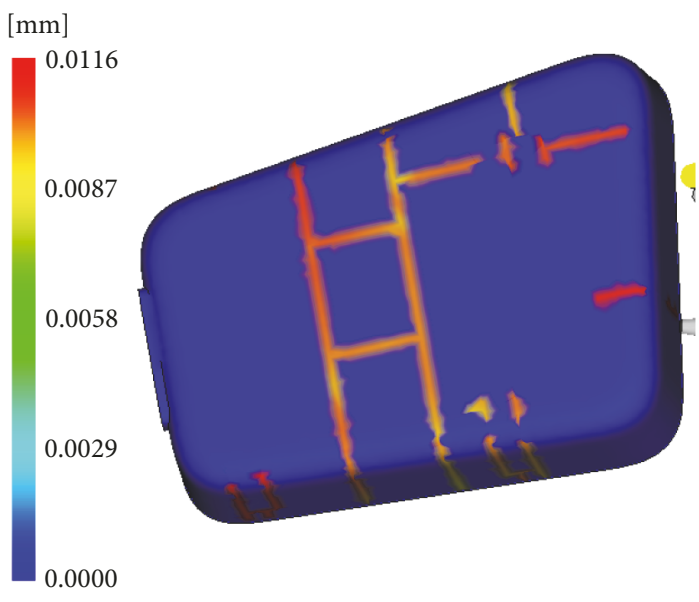

(a)

$[\mathrm{mm}]$

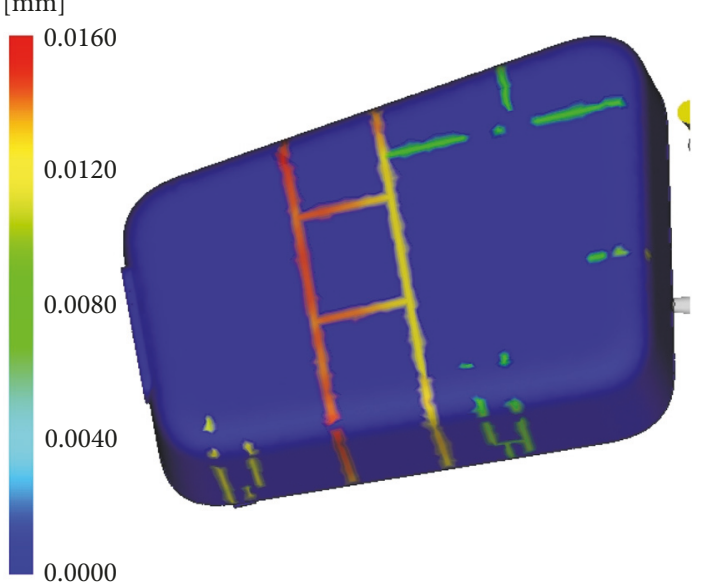

(c)

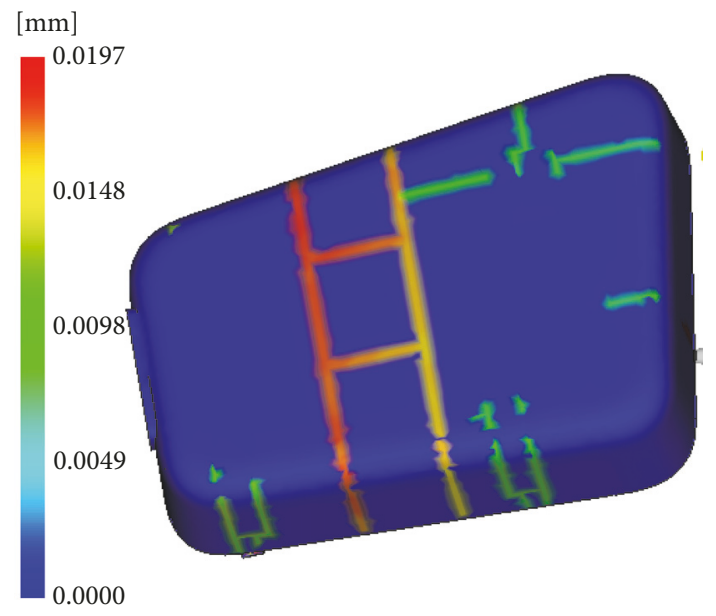

(e)

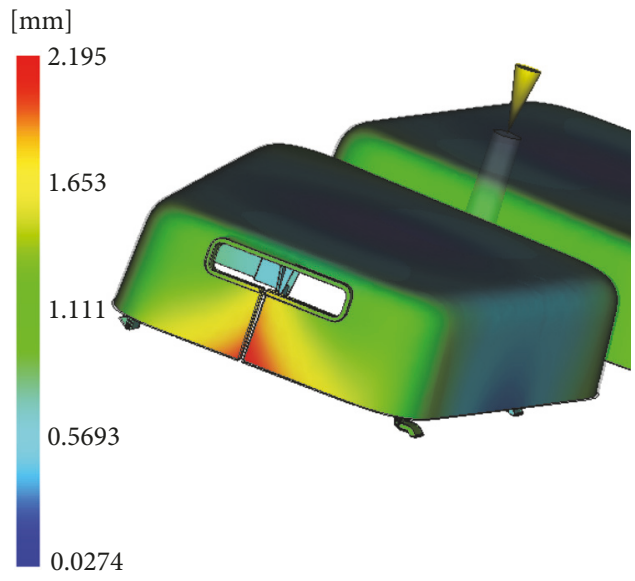

(b)

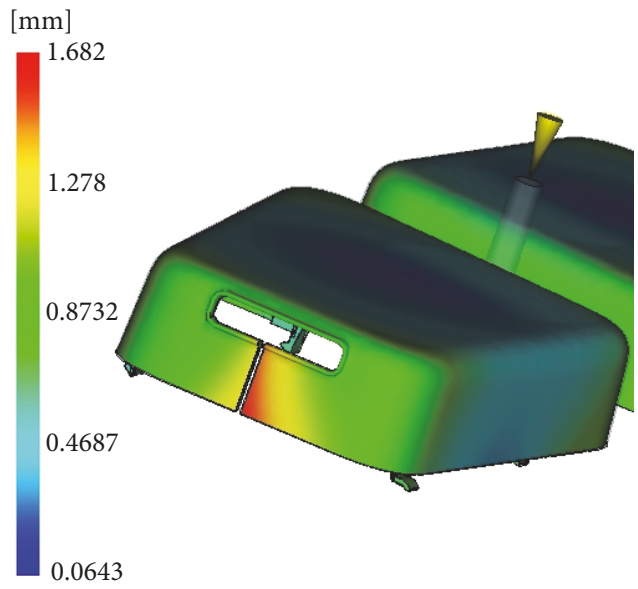

(d)

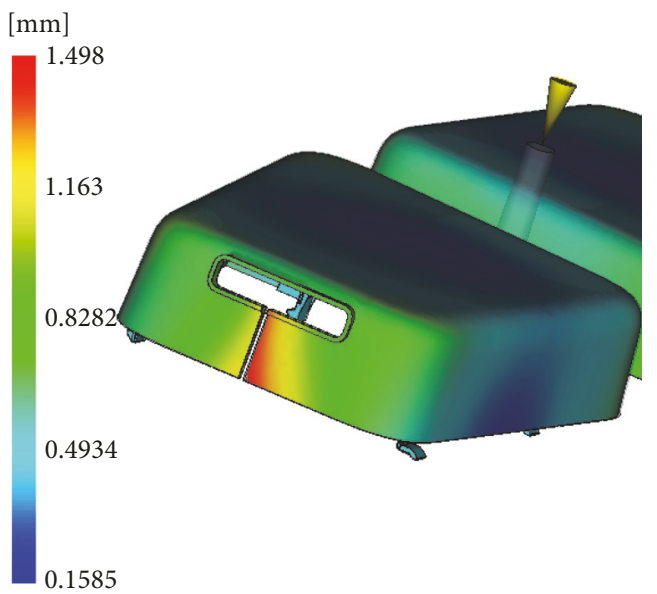

(f)

FIGURE 13: Simulation results under the parameters in Table 6: (a) sink marks and (b) warpage under Level “-2", (c) sink marks and (d) warpage under Level "0", and (e) sink marks and (f) warpage under Level "2". 


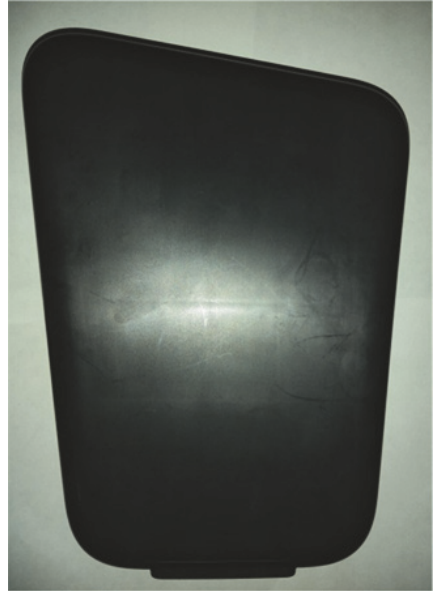

(a)

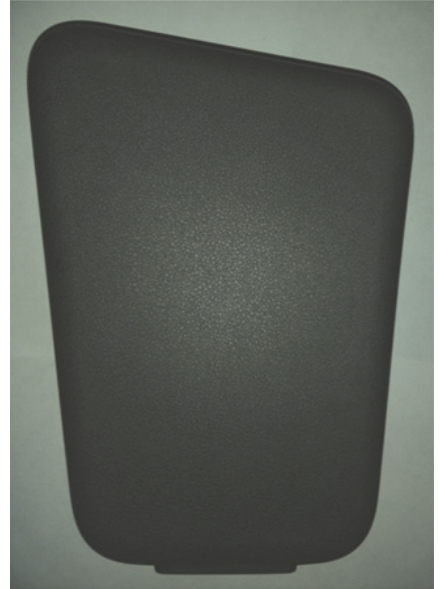

(b)

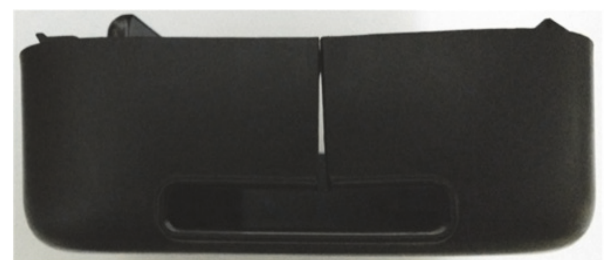

(c)

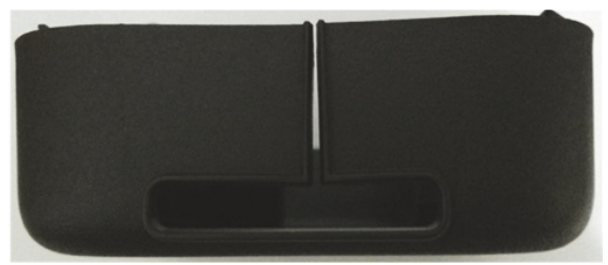

(d)

FIGURE 14: Comparison of the cover plate before and after optimization: (a) surface sink marks before optimization, (b) surface sink marks after optimization, (c) warpage before optimization, and (d) warpage after optimization.

TABLE 9: Regression-coefficient evaluation for the sink marks.

\begin{tabular}{lcccc}
\hline Term & Coeff & SE coeff & T & P \\
\hline Constant & 0.015875 & 0.00013 & 122.56 & 0 \\
A & -0.000292 & 0.00015 & -1.95 & 0.062 \\
B & 0.000042 & 0.00015 & 0.28 & 0.783 \\
C & 0.003042 & 0.00015 & 20.34 & 0 \\
D & -0.000042 & 0.00015 & -0.28 & 0.783 \\
E & -0.000625 & 0.00015 & -4.18 & 0 \\
\hline
\end{tabular}

minimal solution, point 4 is the dominant solution, because both $\mathrm{f} 1$ and $\mathrm{f} 2$ of point 4 are smaller than the other solutions, where $\mathrm{f} 1$ and $\mathrm{f} 2$ are two objective functions of the problem. Points 2 and 3 are nondominated solutions for each other. f1 of point 2 is smaller than point 3 , but $\mathrm{f} 2$ of point 2 is greater than point 3 .

A.2. Pareto Optimal Set. If a solution $\mathrm{p}$ dominates $\mathrm{q}$, the rank of $\mathrm{p}$ is smaller than $\mathrm{q}$. If two solutions are nondominated to each other, the ranks of them are the same. The solutions with the rank of 1 (the smallest rank value) are added to a set, named the first front set. The solutions in the first front set are nondominated to each other. The Pareto optimal set is the first front set. As shown in the Figure 16, the curve $\mathrm{A}$ is the Pareto front, and the area $\mathrm{B}$ is the feasible solution domain.

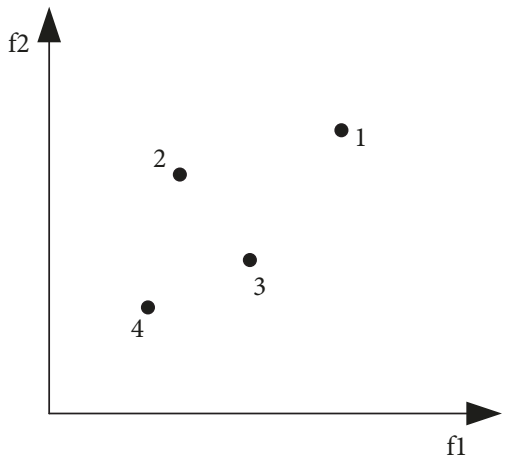

FIGURE 15: Dominant and nondominant solutions.

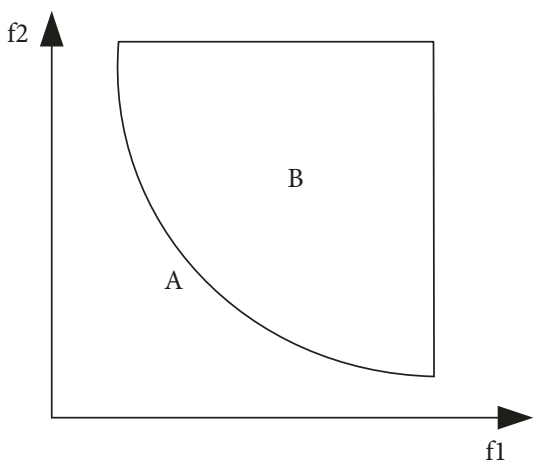

FIgURE 16: Pareto front. 
TABLE 10: Fitting results of the warpage using the four regression models.

\begin{tabular}{lcccc}
\hline & R-sq & R-sq (adjustment) & R-sq (prediction) & $\begin{array}{c}\text { regression } \\
\text { model }\end{array}$ \\
\hline Quadratic & $98.18 \%$ & $91.87 \%$ & $51.38 \%$ & Warpage1 \\
Linear + parabolic & $96.40 \%$ & $94.69 \%$ & $88.19 \%$ & Warpage2 \\
Linear + interaction & $94.80 \%$ & $89.92 \%$ & $52.50 \%$ & Warpage3 \\
Linear & $93.02 \%$ & $91.67 \%$ & $88.81 \%$ & Warpage4 \\
\hline
\end{tabular}

Annotation: the four regression models were followed:

Warpagel $=1.68272-0.03713 \mathrm{~A}-0.00171 \mathrm{~B}-0.04379 \mathrm{C}-0.01929 \mathrm{D}-0.04304 \mathrm{E}+0.00266 \mathrm{~A} \times \mathrm{A}-0.00747 \mathrm{~B} \times \mathrm{B}-0.00522 \mathrm{C} \times \mathrm{C}-0.00609 \mathrm{D} \times \mathrm{D}+0.00553 \mathrm{E} \times \mathrm{E}-$ $0.00419 \mathrm{~A} \times \mathrm{B}+0.00069 \mathrm{~A} \times \mathrm{C}+0.00706 \mathrm{~A} \times \mathrm{D}-0.00094 \mathrm{~A} \times \mathrm{E}+0.00069 \mathrm{~B} \times \mathrm{C}+0.00031 \mathrm{~B} \times \mathrm{D}+0.00081 \mathrm{~B} \times \mathrm{E}+0.00569 \mathrm{C} \times \mathrm{D}+0.00594 \mathrm{C} \times \mathrm{E}+0.00456 \mathrm{D} \times \mathrm{E}$. Warpage $=1.68272-0.03713 \mathrm{~A}-0.00171 \mathrm{~B}-0.04379 \mathrm{C}-0.01929 \mathrm{D}-0.04304 \mathrm{E}+0.00266 \mathrm{~A} \times \mathrm{A}-0.00747 \mathrm{~B} \times \mathrm{B}-0.00522 \mathrm{C} \times \mathrm{C}-0.00609 \mathrm{D} \times \mathrm{D}+0.00553 \mathrm{E} \times \mathrm{E}$. Warpage3 $=1.67478-0.03713 \mathrm{~A}-0.00171 \mathrm{~B}-0.04379 \mathrm{C}-0.01929 \mathrm{D}-0.04304 \mathrm{E}-0.00419 \mathrm{~A} \times \mathrm{B}+0.00069 \mathrm{~A} \times \mathrm{C}+0.00706 \mathrm{~A} \times \mathrm{D}-0.00094 \mathrm{~A} \times \mathrm{E}+0.00069 \mathrm{~B} \times \mathrm{C}$ $+0.00031 \mathrm{~B} \times \mathrm{D}+0.00081 \mathrm{~B} \times \mathrm{E}+0.00569 \mathrm{C} \times \mathrm{D}+0.00594 \mathrm{C} \times \mathrm{E}+0.00456 \mathrm{D} \times \mathrm{E}$.

Warpage $4=1.67478-0.03713 \mathrm{~A}-0.00171 \mathrm{~B}-0.04379 \mathrm{C}-0.01929 \mathrm{D}-0.04304 \mathrm{E}$.

TABLE 11: Regression-coefficient evaluation for the warpage.

\begin{tabular}{lcccc}
\hline Term & Coeff & SE coeff & $\mathrm{T}$ & $\mathrm{P}$ \\
\hline Constant & 1.68272 & 0.00623 & 269.97 & 0 \\
$\mathrm{~A}$ & -0.03713 & 0.00319 & -11.64 & 0 \\
$\mathrm{~B}$ & -0.00171 & 0.00319 & -0.54 & 0.598 \\
$\mathrm{C}$ & -0.04379 & 0.00319 & -13.73 & 0 \\
$\mathrm{D}$ & -0.01929 & 0.00319 & -6.05 & 0 \\
$\mathrm{E}$ & -0.04304 & 0.00319 & -13.49 & 0 \\
$\mathrm{~A} * \mathrm{~A}$ & 0.00266 & 0.00289 & 0.92 & 0.367 \\
$\mathrm{~B} * \mathrm{~B}$ & -0.00747 & 0.00289 & -2.59 & 0.017 \\
$\mathrm{C} * \mathrm{C}$ & -0.00522 & 0.00289 & -1.81 & 0.085 \\
$\mathrm{D} * \mathrm{D}$ & -0.00609 & 0.00289 & -2.11 & 0.047 \\
$\mathrm{E} * \mathrm{E}$ & 0.00553 & 0.00289 & 1.92 & 0.069 \\
\hline
\end{tabular}

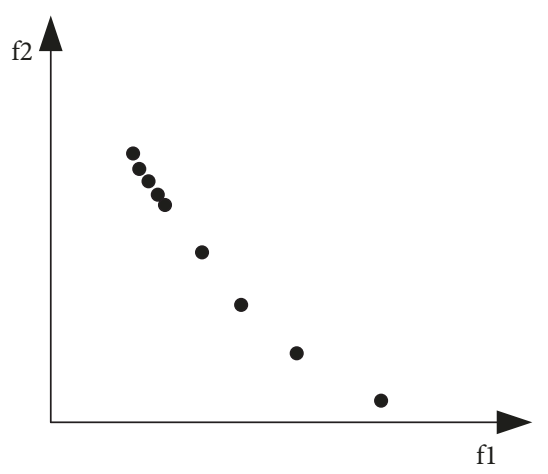

Figure 17: Crowding distance.

A.3. Crowding Distance. The crowding distance is used to describe the distance between two solutions in a front set. Obviously, the greater the distance is, the less crowded the solutions are, and the better the population diversity is. As shown in Figure 17, the crowding distance on the left side of the Pareto front is small, and many solutions are gathered in this area. This result is not ideal, so the crowding distance needs to be controlled. The calculation is described in Appendix B.

\section{B. Algorithms of the Key Operators in the Multiobjective Genetic Optimization Module}

B.1. Selection. The selection operator applied tournament selection algorithm based on rank and crowding distance. The algorithm is as in Algorithm 1.

B.2. Nondominated Sorting. Nondominated sorting was used to sort individuals in the combined population of parent and child populations so as to obtain the rank of each individual. The algorithm is as in Algorithm 2.

B.3. Crowding Distance Calculating. The process of the crowding distance calculation is as follows.

Step 1. Enter the population 'pop', the number of rows 'popSize', and the number of columns 'numDatta'. 'popSize' is the number of individuals, and 'numDatta' is the number of objective functions.

Step 2. Map the i-th objective function value of all individuals to interval $(-1,1)$.

Step 3. The mapped function values are sorted in ascending order.

Step 4. The crowding distance of the two ends is defined as infinite. The distance of other individuals is the function value difference of its two neighbor individuals, and thus the crowding distance of each individual under the $\mathrm{i}$-th function value is obtained.

Step 5. Repeat Step 2, 3, and 4 until all objective functions have been calculated.

Step 6. The crowding distance for an individual is the sum of the calculated crowding distances for all objective functions.

\section{Data Availability}

The data used to support the findings of this study are included within the article 


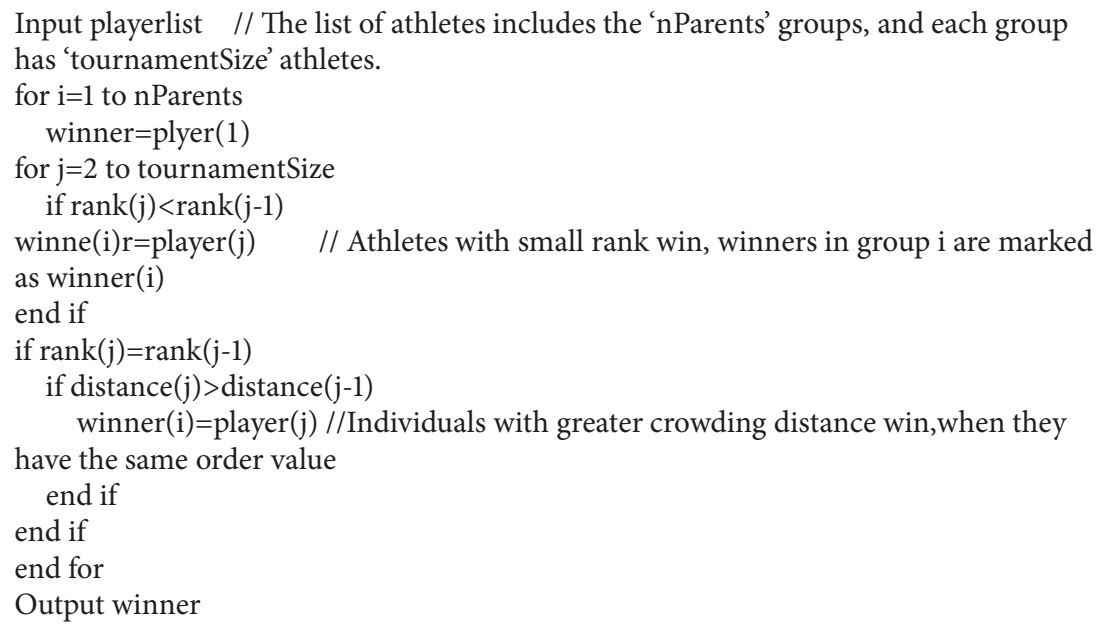

Algorithm 1: Selection tournament.

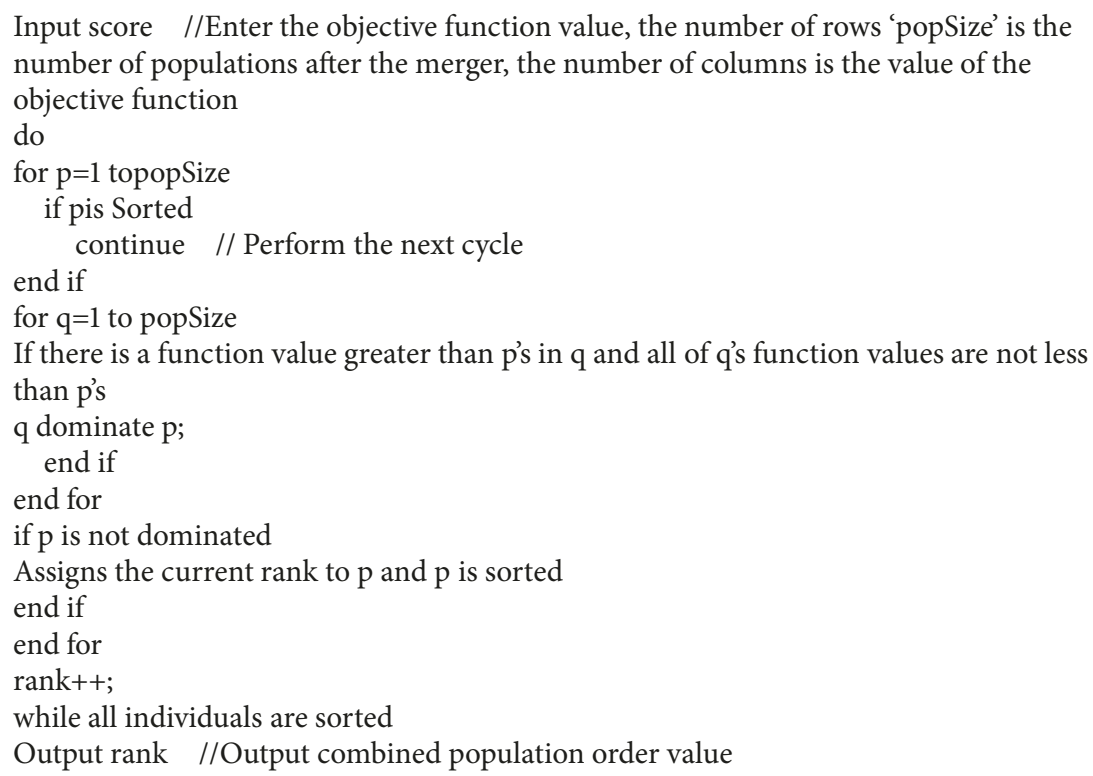

Algorithm 2: NonDominatedRank.

\section{Conflicts of Interest}

The authors declare that there are no conflicts of interest regarding the publication of this paper.

\section{Acknowledgments}

The authors would like to acknowledge the financial support from the National Natural Science Foundation Council of China (Grant no. 51775398), the 111 Project (Grant no. B17034), the Program for Innovative Research Team in University of Education Ministry (Grant no. IRT_17R83), Nature Science Foundation of Hubei Province (Grant no. 2018CFB595), and the Fundamental Research Funds for the
Central Universities (Grants nos. WUT: 2018III074GX and 2018III067GX).

\section{References}

[1] W. Guo, L. Hua, and H. Mao, "Minimization of sink mark depth in injection-molded thermoplastic through design of experiments and genetic algorithm," The International Journal of Advanced Manufacturing Technology, vol. 72, no. 1-4, pp. 365375, 2014.

[2] D. Mathivanan, M. Nouby, and R. Vidhya, "Minimization of sink mark defects in injection molding process - Taguchi approach," International Journal of Engineering Science \& Technology, vol. 2, no. 2, 2010. 
[3] Y. Zhao, P. Zhao, J. Zhang, J. Huang, N. Xia, and J. Fu, “On-line measurement of clamping force for injection molding machine using ultrasonic technology," Ultrasonics, vol. 91, pp. 170-179, 2019.

[4] Z. Jiao, P. Xie, W. Yang, and X. Wang, "Automatic control and energy-saving mechanism of internal circulation twoplaten injection molding machine," in Proceedings of the 2010 International Conference on Mechanic Automation and Control Engineering, MACE2010, pp. 5491-5494, China, June 2010.

[5] P. Zhao, Y. Zhao, H. Kharbas et al., "In-situ ultrasonic characterization of microcellular injection molding," Journal of Materials Processing Technology, vol. 270, pp. 254-264, 2019.

[6] P. Zhao, W. M. Yang, X. M. Wang, J. G. Li, B. Yan, and J. Z. Fu, "A novel method for predicting degrees of crystallinity in injection molding during packing stage," Proceedings of the Institution of Mechanical Engineers, Part B: Journal of Engineering Manufacture, vol. 233, no. 1, pp. 204-214, 2019.

[7] J. F. Zhang, P. Zhao, Y. Zhao, J. Y. Huang, N. Xia, and J. Z. $\mathrm{Fu}$, "On-line measurement of cavity pressure during injection molding via ultrasonic investigation of tie bar," Sensors and Actuators A: Physical, vol. 285, pp. 118-126, 2019.

[8] N. Li, H. B. Liu, and H. T. Wu, "The deformation analysis and optimization of the injection molded parts based on the moldflow and minitab software," Advanced Materials Research, vol. 753-755, no. 6, pp. 1180-1183, 2013.

[9] B. H. Lee and B. H. Kim, "Optimization of part wall thicknesses to reduce warpage of injection-molded parts based on the modified complex method," Polymer-Plastics Technology and Engineering, vol. 34, no. 5, pp. 793-811, 1995.

[10] B. Ozcelik and T. Erzurumlu, "Determination of effecting dimensional parameters on warpage of thin shell plastic parts using integrated response surface method and genetic algorithm," International Communications in Heat and Mass Transfer, vol. 32, no. 8, pp. 1085-1094, 2005.

[11] B. Ozcelik and T. Erzurumlu, "Comparison of the warpage optimization in the plastic injection molding using ANOVA, neural network model and genetic algorithm," Journal of Materials Processing Technology, vol. 171, no. 3, pp. 437-445, 2006.

[12] S. Tang, Y. Tan, S. Sapuan, S. Sulaiman, N. Ismail, and R. Samin, "The use of Taguchi method in the design of plastic injection mould for reducing warpage," Journal of Materials Processing Technology, vol. 182, no. 1-3, pp. 418-426, 2007.

[13] Y. Gao and X. Wang, "An effective warpage optimization method in injection molding based on the Kriging model," The International Journal of Advanced Manufacturing Technology, vol. 37, no. 9-10, pp. 953-960, 2008.

[14] B. Farshi, S. Gheshmi, and E. Miandoabchi, "Optimization of injection molding process parameters using sequential simplex algorithm," Materials and Corrosion, vol. 32, no. 1, pp. 414-423, 2011.

[15] C. Wang, J. Shen, and H. Zhu, "Warpage simulation and optimization for the shell of color liquid crystal display monitor based on Moldflow," in Proceedings of the 2011 2nd International Conference on Mechanic Automation and Control Engineering, MACE 2011, pp. 924-927, China, July 2011.

[16] S. Ni, "Preventing sink marks of injection molded parts using CAE analysis," in Proceedings of the ANTEC, pp. 453-455, 2000.

[17] D. Mathivanan and N. S. Parthasarathy, "Sink-mark minimization in injection molding through response surface regression modeling and genetic algorithm," The International Journal of Advanced Manufacturing Technology, vol. 45, no. 9-10, pp. 867874, 2009.
[18] Q. Feng and X. Zhou, "Automated and robust multi-objective optimal design of thin-walled product injection process based on hybrid RBF-MOGA," The International Journal of Advanced Manufacturing Technology, vol. 101, no. 9-12, pp. 2217-2231, 2019.

[19] H. X. Li, K. Liu, D. Y. Zhao, M. J. Wang, Q. Li, and J. H. Hou, "Multi-objective optimizations for microinjection molding process parameters of biodegradable polymer stent," Materials, vol. 11, no. 11, p. 16, 2018.

[20] S. Farahani, A. Yelne, F. Akhavan Niaki, and S. Pilla, Numerical simulation for the hybrid process of sheet metal forming and injection molding using smoothed particle hydrodynamics method, 2019.

[21] S. Farahani, A. F. Arezoodar, B. M. Dariani, and S. Pilla, "An analytical model for nonhydrostatic sheet metal bulging process by means of polymer melt pressure," Journal of Manufacturing Science and Engineering, vol. 140, no. 9, 2018.

[22] H. Kazan, S. Farahani, and S. Pilla, Influences of process parameters on penetration in a hybrid single shot manufacturing of carbon fiber/epoxy- polypropylene structure, 2019.

[23] F. Yin, H. Mao, L. Hua, W. Guo, and M. Shu, "Back Propagation neural network modeling for warpage prediction and optimization of plastic products during injection molding," Materials and Corrosion, vol. 32, no. 4, pp. 1844-1850, 2011.

[24] K. Deb, A. Pratap, S. Agarwal, and T. Meyarivan, "A fast and elitist multiobjective genetic algorithm: NSGA-II," IEEE Transactions on Evolutionary Computation, vol. 6, no. 2, pp. 182197, 2002.

[25] K. Miettinen, Nonlinear Multiobjective Optimization, Birkhaüser Verlag, 1999.

[26] E. Zitzler and L. Thiele, "Multiobjective optimization using evolutionary algorithms - a comparative case study," in Proceedings of the International Conference on Parallel Problem Solving from Nature, vol. 1498, pp. 292-301, 1998.

[27] H. Oktem, T. Erzurumlu, and I. Uzman, "Application of Taguchi optimization technique in determining plastic injection molding process parameters for a thin-shell part," Materials and Corrosion, vol. 28, no. 4, pp. 1271-1278, 2007.

[28] T. Tabi, A. Suplicz, F. Szabo et al., "The analysis of injection molding defects caused by gate vestiges," Express Polymer Letters, vol. 9, no. 4, pp. 394-400, 2015.

[29] V. Leo and C. Cuvelliez, "The effect of the packing parameters, gate geometry, and mold elasticity on the final dimensions of a molded part," Polymer Engineering \& Science, vol. 36, no. 15, pp. 1961-1971, 1996.

[30] J. Dobránsky, P. Baron, M. KoČiško, L. BĚhálek, and E. Vojnová, "Solving depressions formed during production of plastic molding," Metalurgija, vol. 54, no. 3, pp. 496-498, 2015.

[31] M. Wegrzyn, O. Sahuquillo, A. Benedito, and E. Gimenez, "Morphology, mechanical performance, and nanoindentation behavior of injection molded PC/ABS-MWCNT nanocomposites," Journal of Applied Polymer Science, vol. 132, no. 22, 2015.

[32] T. Erzurumlu and B. Ozcelik, "Minimization of warpage and sink index in injection-molded thermoplastic parts using Taguchi optimization method," Materials and Corrosion, vol. 27, no. 10 , pp. 853-861, 2006. 


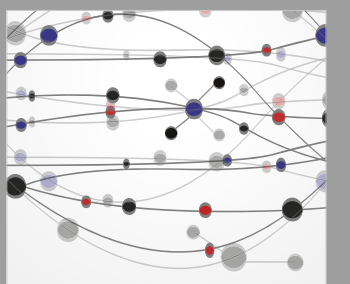

The Scientific World Journal
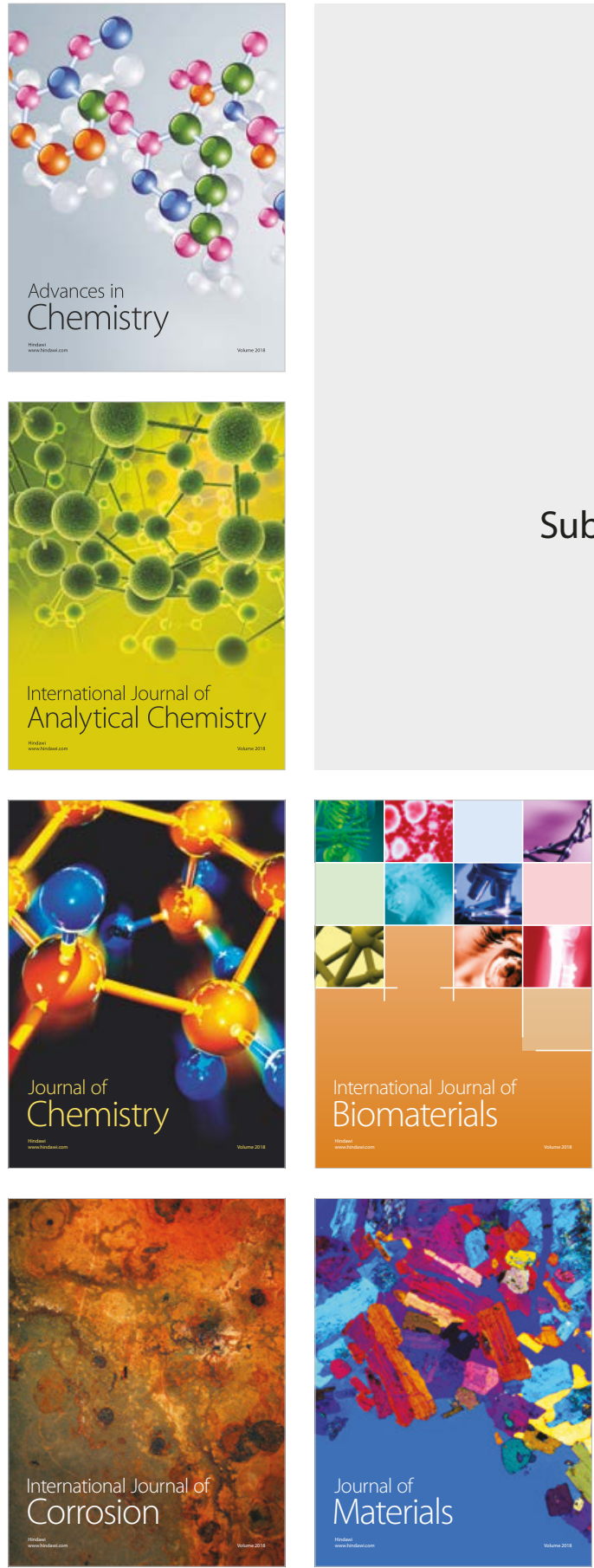

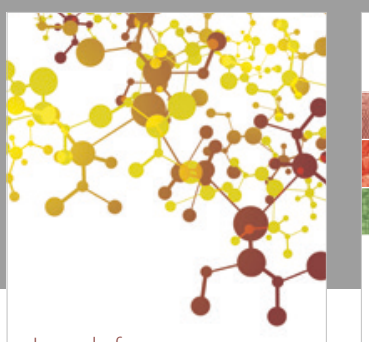

Journal of

Applied Chemistry
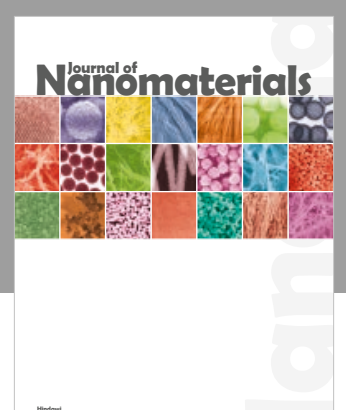

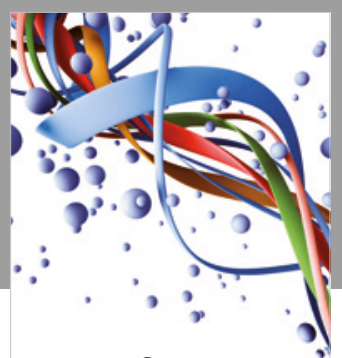

Scientifica

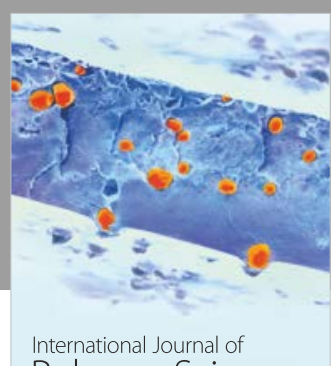

Polymer Science

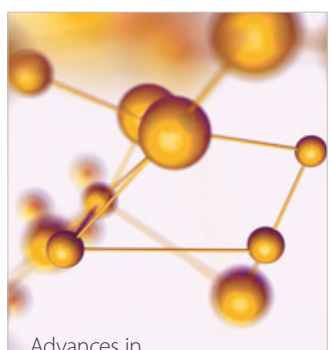

Physical Chemistry
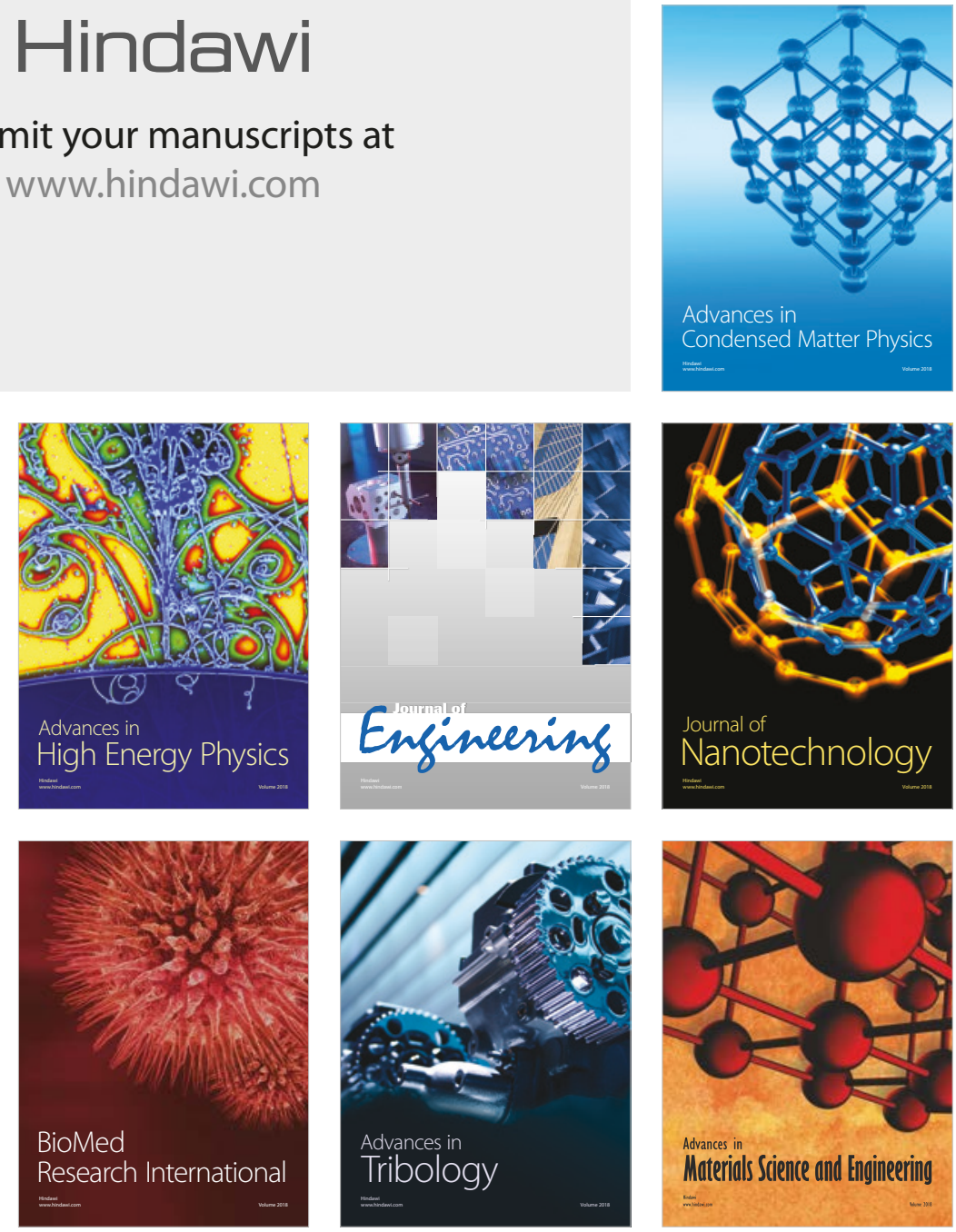